\title{
PULTRUSION OF FIBRE REINFORCED THERMOPLASTIC PRE-IMPREGNATED MATERIALS
}

\author{
$\underline{\text { P. J. Novo }}^{1 *}$, J F. Silva ${ }^{2}$, J. P. Nunes ${ }^{3}$ and A. T. Marques ${ }^{4}$ \\ ${ }^{1}$ Dep. of Mechanical Engineering, ESTG, Polytechnic Institute of Leiria, 2411-901 Leiria, \\ Portugal \\ ${ }^{2}$ Dep. of Mechanical Engineering, ISEP, 4200-072 Porto, Portugal \\ ${ }^{3}$ Institute of Polymers and Composites/I3N, Minho University, 4800-058 Guimaraes, Portugal \\ ${ }^{4}$ DEMEGI / FEUP, 4200-465 Porto, Portugal \\ * Corresponding author (e-mail: pnovo@estg.ipleiria.pt; phone: +351 917633616)
}

Keywords: towpreg; PCT; pre-impregnated materials; pultrusion; thermoplastic composite; mechanical properties

\begin{abstract}
Fibre pre-impregnated thermoplastic materials produced by different methods and processing conditions were used to produce composites using pultrusion and compression moulding. The processing windows used to produce these materials and composite profiles were optimised by using method of Taguchi/ DOE (Design of Experiments). 1 bmposites were manufactured by pultrusion and compressing moulding and subsequently submitted to mechanical testing and microscopy analysis. The obtained results were compared with the expected theoretical ones predicted from the rule of mixtures and with those of similar conventional available materials. The results obtained shown that produced composites have adequate properties for common and structural engineering markets.
\end{abstract}




\section{Page: 2}

T Number: 1

It was already mentioned in the first sentence. Please correct this.

Text corrected according to reviwer's suggestion. (Highlighted in the attached file). 


\section{Introduction}

Although only recently thermoplastic matrices have been used in long and continuous fibre reinforced

composites replacing 1 ith success thermosetting matrices, the number of their applications is increasing due to their better ecological and mechanical performance. Composites with thermoplastic matrices 2 fers increased fracture toughness, higher damage tolerance, short processing cycle times and excellent environmental stability. They are recyclable, post-formable and can be joined by welding. The use of long/continuous fibre reinforced thermoplastic matrix composites involves, however, great technological and scientific challenges since thermoplastics present much higher viscosity than thermosettings, which makes much difficult and complex the impregnation of reinforcements and consolidation tasks [1-6].

Today, two major technologies are being used to allow wet reinforcing fibres with thermoplastic polymers [1, 4-6]: i) the direct melting of the polymer and, ii) the intimate fibre/matrix contact prior to final composite fabrication. Continuous fibre reinforced thermoplastic matrix pre-impregnated tapes (PCT's) are, for example, produced by direct melting processes. Alternatively, intimate contact processes allow producing cheap and promising pre-impregnated materials, such as, commingled fibres and powder coated towpregs. Sometimes, thermoplastic compatibilizers are added to the matrices to improve their adhesion and facilitate impregnation to reinforcements [7].

This work studies and compares the processability of final composite parts by using three different pre-impregnated materials 3 oduced by each one of the above mentioned wetting techniques. All studied pre-impregnated materials were based on a continuous fibres (carbon and glass) reinforced polypropylene

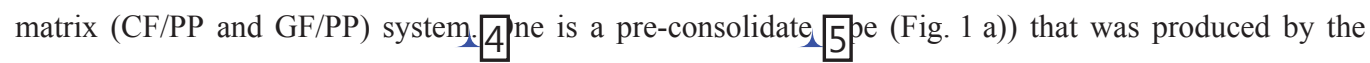
melting process (cross-head extrusion) [8]. From the other two produced by fibre/matrix intimate contact methods, one is a commercially available commingled fibres product (Fig. 1 b) and the other a towpreg (Fig. 1 c)) produced by our own developed dry coating line [9]. 6. litrusion and compression moulding were the selected manufacturing methods for processing all these pre-impregnated materials into composite parts.

The optimization of both processes was made by studying the influence of the most relevant processing parameters in the final properties of the produced pre-impregnated materials and composites. The method of Taguchi / DOE (Design of Experiments) was used to achieve this aim.

The possibility of using maleic anhydride as compatibilizer of carbon and glass fibre reinforced polypropylene composites (CF/PP and GF/PP) was also analysed in the present work.

Towpregs were characterized by scanning electron microscopy (SEM), visual analysis and their polymer mass contents were determined. The final composite parts were also submitted to tensile, interlaminar and flexural tests, as well as calcination and optical microscopy tests and the results were 


\section{Page: 3}

T Number: 1 not clear, please correct. Text corrected according to reviwer's suggestion. (Highlighted in the attached file).

T Number: 2 offer Text corrected according to reviwer's suggestion. (Highlighted in the attached file).

T Number: 3 not clear. There are two techniaues mentioned above?

According to the suggestion, compression molding was removed from the final

T. Number: 4 paper text. , respectively.Text corrected according to reviwer's suggestion. (Highlighted in the attached file).

T. Number: 5 d Text corrected according to reviwer's suggestion. (Highlighted in the attached file).

T Number: 6

not agreed with title? Title of the manuscript says "pultrusion". What is the reason that the authours used compression molding?

According to the suggestion, compression molding was removed from the final paper text. 
compared with theoretical ones that can be predicted by using the ROM (Rule Of Mixtures) and 1 her traditional materials.

\section{Experimental}

\subsection{Raw Materials}

The following raw materials were used to produce CF/PP pre-impregnated materials for this work: i) a PP powder ICORENE 9184B $\mathrm{P}^{\circledR}$ and carbon fibre roving M30 SC ${ }^{\circledR}$ from the ICO Polymers and TORAY, respectively, were used to produce the CF/PP towpregs, ii) PP powder Moplen RP348U ${ }^{\circledR}$ from Basell and the carbon fibre roving already mentioned were used to manufacture the CF/PP PCT tapes.

For the GF/PP towpregs, a 2400 Tex type E fibre rovings from Owens Corning and Icorene ${ }^{\circledR}$ 9184B P polypropylene from ICO Polymers France were used. Also, the GF/PP PCT tapes were manufactured with glass fibres (TufRov 4599) from PPG Industries and a polypropylene matrix (Moplen RP348U) from Basell.

Commercial commingled GF/PP fibres TWINTEX® R PP 60 B 1870 FU from Owens Corning were also used in the production of pultrusion thermoplastic composite profiles, as reference of a current commercially available pre-impregnated product.

Some batches of CF/PP and GF/PP towpregs were also produced using PP powder (ICORENE 9184B $\mathrm{P}^{\circledR}$ ) blended with 1\% in mass content of maleic anhydride S $4729608707^{\circledR}$ from Merck Schuchardt OHG, in order to assess the possible enhancement of fibre/matrix adhesion [10-14].

Tables 1 and 2 summarise relevant properties of the polypropylene, glass and carbon fibres used in present work to produce pre-impregnated raw materials (towpregs and PCT's). Table 3 shows the manufacturer datasheets properties of TWINTEX ${ }^{\circledR}$.

\subsection{Production of Thermoplastic Matrix Pre-Impregnated Products}

The dry powder coating equipment used to produce fibre reinforced towpregs is schematically depicted in Figure $2[9,15]$.

The pre-consolidated tapes (PCT's) used in this work were produced in a cross-head extrusion equipment (see Fig.3) from our own laboratories [8]. Using this equipment, it was possible to produce the tapes (PCT's) pre-impregnated raw-materials. The overview of their main properties is given in Table 4.

\subsubsection{CF/PP towpregs production and optimization}

In order to optimize the production of CF/PP powder coated towpregs, different processing variables combinations were experimented and the number of trials optimized using the Taguchi approach. The studied operational parameters were:

- heating oven temperature $\left(600,650\right.$ and $\left.700{ }^{\circ} \mathrm{C}\right)$; consolidation oven temperature $\left(350,400\right.$ and $\left.450{ }^{\circ} \mathrm{C}\right)$; linear pull speed $(4,6$ and $8 \mathrm{~m} / \mathrm{min})$. 


\section{Page: 4}

T Number: 1

not clear. Please give some examples for other traditional materials

Examples were given 
The Taguchi approach was applied to the towpregs production process in order to obtain the condition that maximizes polymer powder content.

The polymer mass fraction in the towpregs, $\omega_{p}$, was determined by weighting towpreg strips produced in those different conditions, using equation 1 :

$$
\omega_{p}=\frac{W_{t}-W_{f}}{W_{t}}
$$

where $W_{t}$ and $W_{f}$ are the measured unit length weights of the towpreg strip and fibre roving, respectively.

Table 5 shows the used processing conditions and obtained results, according to the established design of experiments. The average polymer mass content in towpregs, established by the design of experiences was $34.5 \%$ (Table 5).

The 1 ains 2 ects of the processing variables on the results can be seen from Figure 4.

The optimal condition obtained from Taguchi method application led to the following operating parameters selection: heating oven temperature and consolidation oven temperatures of $700{ }^{\circ} \mathrm{C}$ and $400^{\circ} \mathrm{C}$ respectively, and a linear pulling speed of $4 \mathrm{~m} / \mathrm{min}$. Using this optimal operative condition, the amount of polymer should increase up to $45.6 \%$. However, the operative condition that was chosen as optimal had a line pull speed of $6 \mathrm{~m} / \mathrm{min}$ allowing a high rate of production, lower processing problems and sufficiently levels of polymer content $3 \%$, enough for the of use of towpregs in the pultrusion process). Also, the addition of $1 \%$ of maleic anhydride to the PP polymer had no influence on the towpreg polymer mass fraction. Table 6 summarizes the determined towpreg properties obtained with the combination of 4 timal parameters.

\subsubsection{GF/PP towpregs production and optimization}

To try maximizing the polymer powder content in the towpregs the following processing conditions were varied within the next ranges: i) convective oven temperature $\left({ }^{\circ} \mathrm{C}\right): 650$ - 700; ii) Consolidation furnace temperature $\left({ }^{\circ} \mathrm{C}\right): 350$ - 450; iii) Coating line pulling speed (m/min): $4-6$.

From the polymer mass fractions obtained in produced towpreg strips it was possible to establish as optimal the following operating parameters: convective and consolidation oven temperatures of $700{ }^{\circ} \mathrm{C}$ and $400^{\circ} \mathrm{C}$ respectively, and a linear pulling speed of $6 \mathrm{~m} / \mathrm{min}$. In such operational conditions the GF/PP towpregs were continuously produced with polymer mass content of $30.7 \%$.

Unexpectedly, very low polymer mass fractions ( $\sim 10 \%-16 \%)$ were obtained when PP powder with $1 \%$ of maleic anhydride was used to produce GF/PP towpregs. Hence, the idea of using this additive to improve adhesion of the PP matrix to the glass fibres was abandoned. Table 6 summarizes the determined towpreg properties obtained with the combination of selected parameters. 


\section{Page: 5}

T Number: 1

main Text reformulated according to reviwer's suggestion. (Highlighted in the attached file).

T Number: 2

Please elaborate more on Figure 4.

T Number: 3

Text reformulated according to reviwer's suggestion. (Highlighted in the attached file).

authors should justify this argument. Why $40 \%$ is enough?

T Number: 4

Argument justified supported by a bibliographic reference. (Highlighted in the attached file).

not clear. Please explicitly mention here what are the optimal parameters?

Text reformulated clarifying the meaning of the sentence. (Highlighted in the attached file). 


\subsection{Pultrusion of pre-impregnated materials}

The towpregs, PCT's and commingled fibres were processed into composite $1_{\mathrm{r}}$ profiles using the laboratorial pultrusion line, Figure $5[10,18]$.

To produce composite profiles, the pre-impregnated materials are guided into the pre-heating furnace to be heated up to the required temperature. Then, they enter in the pultrusion heated die to be heated and consolidated to the required size and, after cooled down in the cooling die to solidify. 2he die temperature distribution profile in order to obtain enhanced final properties can be seen in Figure 6.

In this work, it was designed and manufactured a die to allow producing a $20 \times 2 \mathrm{~mm}^{2}$ bar-shaped profile.

\subsubsection{Towpreg processing}

$\mathrm{CF} / \mathrm{PP}$ towpregs were manufactured by pultrusion into composite bar profiles using the most relevant operating conditions. The Taguchi's/DOE method was applied, maintaining the cooling die at $25^{\circ} \mathrm{C}$, in order to optimize the processing parameters:

i) furnace temperature $\left(160\right.$ or $\left.180^{\circ} \mathrm{C}\right)$; ii) heating die temperature $\left(240\right.$ or $\left.260{ }^{\circ} \mathrm{C}\right)$; iii)linear pull-speed ( 0.2 or $0.3 \mathrm{~m} / \mathrm{min})$.

3 esults have shown that was not possible to produce, in steady, conditions pultruded profiles from towpregs at pultrusion speeds and consolidation die temperatures higher than $0.4 \mathrm{~m} / \mathrm{min}$ and $260{ }^{\circ} \mathrm{C}$, respectively. By using higher values of these two parameters, the process became unsteady, mainly due to reflux and accumulation of the thermoplastic polymer at the entrances of the consolidation and cooling dies.

Table 7 summarizes the flexural test results, as described in 4 xt paragraph 2.5.2, obtained with the studied processing conditions according to established in the design of experiments. The variation of the flexural modulus and strength with the selected processing parameters can be seen in Figures 7 and 8 .

The optimal condition concerning flexural stiffness maximization obtained from Taguchi method application led to the following operating parameters selection: furnace and heated die oven temperatures of $160{ }^{\circ} \mathrm{C}$ and $260^{\circ} \mathrm{C}$ respectively, and a linear pulling speed of $0,2 \mathrm{~m} / \mathrm{min}$. For optimizing the flexural strength the obtained 5 rameters combination was: furnace and heated die oven temperatures of $160{ }^{\circ} \mathrm{C}$ and $240^{\circ} \mathrm{C}$ respectively, and a linear pulling speed of $0.3 \mathrm{~m} / \mathrm{min}$.

It is possible to observe that the furnace temperature of $160^{\circ} \mathrm{C}$ lead to the better results. That could be explained by the lower polymer reflux on the entrance of the heated die. The optimal operating conditions to maximize both flexural properties were: furnace and heated die oven temperatures of $160{ }^{\circ} \mathrm{C}$ and $260^{\circ} \mathrm{C}$ respectively, and a linear pulling speed of $0.2 \mathrm{~m} / \mathrm{min}$. 


\section{Page: 6}

T Number: 1

rectangular barText modified according to the reviewer's suggestion (Highlighted in the attached file).

T Number: 2

How did the authors determine the heating die temperatures in Figure 6? Using a thermal camera? Please clarify thisText clarified (Highlighted in the attached file).

T Number: 3

Please make this sentence clear. Too long and there is grammar mistake.

Text modified according to the reviewer's suggestion (Highlighted in the attached file).

T Number: 4

Next paragraph is nIn this section, some of the flexural test results are needed for the determination of the optimal condition following the Taguchi method. We think that it is better to keep this explanation here

T Number: 5 than to move it to the section 3 (results and discussion) parameters combined were:

Text modified according to the reviewer's suggestion (Highlighted in the attached file). 
1 nally, towpregs with additive were also pultruded into composite bars using the condition that optimizes both flexural properties and two more conditions (Table 8), being the results from flexural tests using towpreg pultruded bars with and without maleic anhydride additive shown in Table 9. The use of such additive had no significant influence on the flexural properties.

GF/PP pre-impregnated towpreg rovings were processed by pultrusion into rectangular $20 \times 2\left(\mathrm{~mm}^{2}\right)$ profiles. To determine the best processing window, the main processing conditions were varied, maintaining the cooling die at $25^{\circ} \mathrm{C}$ : i) pre-heating temperature $\left({ }^{\circ} \mathrm{C}\right): \quad 170-180$; ii) pressurization/consolidation die temperature $\left({ }^{\circ} \mathrm{C}\right): 240$ - 300; iii) linear pultrusion speed $(\mathrm{m} / \mathrm{min}): 0.2$ 0.4 .

Results have shown 2 at was not possible to produce, in steady conditions, profiles from towpregs at pultrusion speeds and pressurization/consolidation die temperatures higher than $0.3 \mathrm{~m} / \mathrm{min}$ and $280{ }^{\circ} \mathrm{C}$, respectively. By using highen 3 values the process became unsteady as it was already found for CF/PP towpregs processing. 4. 4 oblems also occurred for temperatures below $270^{\circ} \mathrm{C}$ in the pressurization/consolidation die. By maintaining constant the temperatures in the cooling and pressurization/consolidation dies at $25^{\circ} \mathrm{C}$ and $280^{\circ} \mathrm{C}$, respectively, profiles pultruded in different processing conditions were submitted to the flexural tests (see 2.5.2). 5 s may be seen (Table 10), very similar values of flexural moduli and strengths were found by using pre-heating furnace temperatures and linear pultrusion pulling speeds in the ranges of $170-180\left({ }^{\circ} \mathrm{C}\right)$ and $0.2-0.3 \mathrm{~m} / \mathrm{min}$, respectively. While the slower pultrusion pulling speed of $0.2 \mathrm{~m} / \mathrm{min}$ seemed to generate profiles with higher absolute values, this was not confirmed by the flexural properties divided by the determined fiber volume fraction depicted in two last the columns of Table 10. On the other hand, higher flexural strength values, both in 6 solute and relative terms, were obtained at the higher temperature of $180^{\circ} \mathrm{C}$ in pre-heating furnace. 7 ence, it was concluded to use as optimal pultrusion operating window the following one: i) pre-heating temperature $\left({ }^{\circ} \mathrm{C}\right): 170-180$; ii) pressurization/consolidation die temperature $\left({ }^{\circ} \mathrm{C}\right): 280$; iii) cooling die temperature $\left({ }^{\circ} \mathrm{C}\right): 25 ;$ iv) linear pultrusion speed (m/min): 0.2 - 0.3 .

\subsubsection{Pre-consolidate tapes($\left(\mathrm{PCT}^{\prime} \mathrm{s}\right)$ and Twintex ${ }^{\circledR}$ processing}

PCT's and Twintex $^{\circledR}$ were processed into rectangular $20 \times 2\left(\mathrm{~mm}^{2}\right)$ bar using the already mentioned pultrusion equipment being operating conditions shown in Table 11.

\subsection{8 eated Compression Moulding}

Three different GF/PP fibre reinforced pre-impregnated products were studied and also processed into rectangular $180 \times 180 \times 2\left(\mathrm{~mm}^{3}\right)$ plates. All 9 e-impregnates were cut, weighted and introduced in a 


\section{Page: 7}

T Number: 1

Please make this sentence clear. Too long.

Text modified according to the reviewer's suggestion (Highlighted in the attached file).

T Number: 2

that it was

Text modified according to the reviewer's suggestion (Highlighted in the attached file).

I Number: 3

T Number: 4

What kind of problems?

The found problems were presented (Highlighted in the attached file).

T Number: $\mathrm{b}$

As it is seen in Table 10

The found problems were presented (Highlighted in the attached file).

T Number: 6

Not clear, please make it clear. What is absolute and what is relative term in Table 10?

Absolut and relative terms clarified (Highlighted in the attached file).

T Number: 7

Please paraphrase this sentence, difficult to understand.

Text clarified (Highlighted in the attached file).

T Number: 8

Why heated compression molding is used? This section (Section 2.4) is confusing with the rest of the manuscript which is focusing with the pultrusion process.

Which material is produced using which manufacturing technique. This is not clear in the manuscript:

CF/PP and GF/PP are both manufacturing using pultrusion. Waht is the difference for compression moulding. Please make the manuscript easy to understand and follow.

T Nifile).

Following the reviewr's suggestion, compression molding was discarded (Highlighted in the attached correct this word

Following the reviewr's suggestion, compression molding was discarded (Highlighted in the attached file) 
cavity placed between the heated plates of a $400 \mathrm{kN}$ press. 1 fter a 10 min delay, the press was closed up to a compression force of $200 \mathrm{kN}$. One minute after that, the press plates were cooled down maintaining constant the press closing force. At $30^{\circ} \mathrm{C}$, the press plates were opened and the final composite plate removed from the mould. The unidirectional fibre reinforced composite plates were produced with the following processing conditions:2 press platen temperature $\left({ }^{\circ} \mathrm{C}\right): 250$; ii) pre-heating time (min): 10 ; iii) press closing force $(\mathrm{kN}): 200$; iv) delay at maximum closing force $(\mathrm{min})$ : 1.0 ; v) opening platen temperature $\left({ }^{\circ} \mathrm{C}\right): 30$.

\subsection{Testing}

\subsubsection{Microscopy analysis}

$\mathrm{CF} / \mathrm{PP}$ and GF/PP towpreg 3 mples were characterized by scanning electron microscopy (SEM) to evaluate the adhesion of the polymer powder to the fibres and its distribution. Those samples were coated with a layer of 4 ld with approximately $6.5 \mu \mathrm{m}$ thick, before the observation.

To determine the impregnation quality and to evaluate the fibre distribution and fibre/matrix adhesion of the thermoplastic composites, their cross-sections were studied under optical microscopy. Observations were done using reflected light optical microscopy (Olympus BH-2). A digital camera (Leica DFC200) was used to get the image cross sectional views of the samples.

\subsubsection{Mechanical testing}

Bar samples were submitted to flexural, tensile and interlaminar testing according to the ISO standards 14125, 527 and 14130, respectively. The mechanical properties obtained were compared to the theoretical ones predicted by using the Rule of Mixtures (ROM).

Tensile tests were conducted, according to ISO 527, in a $100 \mathrm{kN}$ universal testing machine at the crosshead speed of $2 \mathrm{~mm} / \mathrm{min}$ using $180 \times 20 \times 2 \mathrm{~mm}^{3}$ rectangular samples. The tensile modulus was determined from the slope of the initial linear portion of the experimental stress/strain curve. A SG Shimadzu ${ }^{\circledR} 50 \mathrm{~mm}$ length strain-gauge was used up to $0.3 \%$ strain, for accurate determination of the tensile modulus. Regarding the determination of tensile strength, it was not possible to proceed with the test until specimen failure due to grip slippage. Hence, new specimen geometry was designed and tested 5 ith good results (Figure 9).

Three-point flexural tests were also conducted on five $100 \times 20 \times 2\left(\mathrm{~mm}^{3}\right)$ composite specimens, using $100 \mathrm{kN}$ universal testing machine and a distance between supports of $80 \mathrm{~mm}$, according to ISO 14125, at a crosshead speed of $1 \mathrm{~mm} / \mathrm{min}$.

Samples with dimensions of $20 \times 20 \times 2\left(\mathrm{~mm}^{3}\right)$, cut from composites processed from each preimpregnated raw material, were submitted to interlaminar shear tests according to ISO 14130 . The tests 


\section{Page: 8}

T Number: 1

Please make this clear. Maybe use a plot showing the pressure profile during pressing. Following the reviewr's suggestion, compression molding was discarded (Highlighted in the attached file).

T Numiner. $<$

It would be clearer if the authors use a plot or araph for this cvcle

Following the reviewr's suggestion, compression molding was discarded (Highlighted in the attached file).

T Number: 3

Produced which technique? Pultrusion or compression moldina?

Following the reviewr's suggestion, compression molding was discarded (Highlighted in the attached file).

T Number: 4

Why a gold material was used? Please make this clear in the manuscript

The usage of gold was explained in the text. (Highlighted in the attached file).

T Number: 5

What does good results mean? How did the authors justify the "good" result?

Explained in the text. (Highlighted in the attached file). 
were conducted in a $50 \mathrm{kN}$ universal testing machine by using an initial pre-load of $1 \mathrm{~N}$ at the crosshead speed of $1 \mathrm{~mm} / \mathrm{min}$ and a $10 \mathrm{~mm}$ span between supports.

\subsubsection{Calcination testing}

Carbon and glass fibre composites mass content was determined by using calcination tests according to the EN ISO 1172. Composite samples, weighting approximately $2 \mathrm{~g}$, were submitted to calcination inside a crucible in a muffle furnace during $10 \mathrm{~min}$ at $620^{\circ} \mathrm{C}$.

\section{Results and Discussion}

Figure 10 1 1 ow SEM micrographs of CF/PP and GF/PP towpregs samples. A good degree of adhesion between both carbon and glass fibres and the polymer powder particles was obtained. Also, a reasonable polymer powder distribution on the fibres was achieved at the optimised operating conditions.

The cross-sections of the pultruded composites were studied under optical Microscopy. As can be seen from Figure 11, all CF/PP composite profiles from towpregs (with and without additive) and PCT's have a reasonable distribution of the reinforcing fibres over the cross-sections. However, large differences in impregnation quality occur between the different samples that are likely to be related, directly, to the impregnation state of pre-impregnated materials used in pultrusion. It may be seen that the impregnation quality of the PCT composite samples is good, presenting almost all fibres completely surrounded ('wetout') by the polymer. Only a few large dry spots were observed. This is most likely due to the good degree of impregnation already achieved in the PCT raw-material tape prior to the pultrusion step.

2 he samples from CF/PP towpreg with additive show a higher quantity of dry zones than the ones without additive.

As Figure 12 shows, it was still possible to distinguish discontinuities on the cross section of pultruded composites from GF/PP towpregs, 3 here it may be seen zones very rich in polymer contrasting with others with much higher quantity of fibres.

The microscopy images taken from the samples of the pultruded composites using GF/PP PCT, TWINTEX $^{\circledR}$ and GF/PP towpreg, are given in Table 12.411 semi-finished products lead to a reasonable distribution of the reinforcing fibres over the cross-sections, 5 though small improvements in fibre distribution can be observed going from PCT through TWINTEX ${ }^{\circledR}$ to towpreg composites.

It may be seen that the impregnation quality of the PCT composite samples is excellent, 6 esenting almost all fibres completely surrounded ('wet-out') by the polymer, hardly showing any dry spots in the pultruded samples.

The TWINTEX ${ }^{\circledR}$-based samples also show a very good impregnation of the fibre. This is likely due to the intimate contact between the individual dry glass and PP fibres prior to the final pultrusion stage, making the effective remaining impregnation distance 7 hen melting the polymer very small, which leads 


\section{Page: 9}

T Number: 1

shows Text modified according to the reviewer's suggestion (Highlighted in the attached file).

T Number: 2

The authors should explain the potential reasons for this.

Potential reasons were explained (Highlighted in the attached file).

T Number: 3

please make this sentence clearer. It is difficult to understand its meaning.

Clarified in figure 12.

T Number: 4

What does it mean? Isn't the samples pultruded completely?

Text clarified (Highlighted in the attached file).

T Number: 5

Please make it clear and more explicit. How should the reader interpret this improvement from Table 12? Text clarified (Highlighted in the attached file).

T Number: 6

Please make it clear and more explicit in Table 12. How should the reader interpret that the PCT is excellent relatina it to Table 12 ?

A caption was added to Table 12 in order to clarify the text.

T Number: 7

Please make this sentence clearer. It is difficult to understand "when melting the polymer very small"? Text clarified (Highlighted in the attached file). 
to an easier consolidation. However, 1 me larger dry spots were observed between the glass fibres at larger magnifications, showing an overall impregnation quality poor when compared with the one observed in the PCT tape based pultruded composites. Finally, the depicted towpreg-based composite samples exhibit larger apparent dry zones. This is most likely due to the uneven distribution of the dry polymer powder in the towpreg, prior to pultrusion. It seems to be harder to bridge the large distances of dry glass fibre during pultrusion, which results on bigger unimpregnated zones in the pultruded composites.

Tables 13 and 14 summarize all experimentally results obtained from the CF/PP and GF/PP unidirectional composites processed by pultrusion and compression moulding, respectively, from the preimpregnated products under study. To better evaluate and compare the mechanical properties obtained on the composites processed from the different pre-impregnated products studied, Tables 13 and 14 also present theoretical expected values and relative values of specific properties.

The theoretical values of moduli, $E$, 2 as directly obtained from the rule of mixtures using the rawmaterial properties presented in Tables 1, 2 and 3, following the Eq. 2:

$$
E=E_{f} \cdot v_{f}+E_{p} \cdot\left(1-v_{f}\right)
$$

where, $E_{f}, E_{p}$ and $v_{p}$ are the fibre modulus, polymer modulus and fibre volume fraction, respectively.

As can be seen from Tables 13 and 14, the experimental moduli obtained from de CF/PP and GF/PP composites are in good agreement with the predicted theoretical ones. Some experimental values are even higher than the theoretical expected ones. This can be explained considering that the volume fraction content of some samples can be higher than the determined by the calcination tests.

Using the proposed new geometry (Figure 9) for the tensile test specimens, it was possible to reach 3 eaking loads and therefore determine their tensile strengths.

Analysing 4 ble 13, one can conclude that composites processed from the CF/PP PCT's demonstrated 5 have better flexural and interlaminar shear strengths than those produced from CF/PP towpregs. From Table 14, it is possible to conclude that commingled fibres (TWINTEX ${ }^{\circledR}$ ) presented, in general, better properties and had also shown to be more adjusted to commercial application demands and to be easily processed into final composites by the currently used manufacturing methods, probably 6. cause their easy consolidation.

In any case, worse flexural strength and modulus results were found in GF/PP towpreg and PCT pultruded composites, respectively. These 7 wer results obtained in the flexural tests are probably consequence of the inferior degree of impregnation observed in the towpreg based composites and, in the 8 se of PCT tape based composites, result from the higher rich polymer regions exhibited by this material in its outside layers. 


\section{Page: 10}

T Number: 1 where? show in the corresponding figure or table (Table 12?)?

Table 12 (Highlighted in the attached file).

T Number: 2 were directly

Text modified according to the reviewer's suggestion (Highlighted in the attached file).

T Number: 3

failure

Text modified according to the reviewer's suggestion (Highlighted in the attached file).

T Number: 4

Tahlo

Text modified according to the reviewer's suggestion (Highlighted in the attached file).

T Number: 5

T Number: 6

due to

Text modified according to the reviewer's suggestion (Highlighted in the attached file).

T Number: 7

as compared to what? Answered in the text.

T Number: 8

too complex and long sentence. Please make it simple and clear.

In flexure, if in the sample thickness the top and bottom layers were rich in polymer (lack of fibres), the flexure stiffness and strength will decrease significantly comparatively to samples where the impregnated fibres show a good distribution through the thickness 
Nevertheless, the GF/PP pre-impregnated products produced in 1 1 r laboratories (towpregs and PCTs) have already demonstrated very good mechanical behaviour, namely, in terms of stiffness. In fact, the composites manufactured from these products presented experimental moduli values very closed to the theoretical expected ones. 2 hile composites processed from the PCTs demonstrated to have better mechanical strength, those produced from towpregs presented higher moduli. As mechanical strength values are more affected by small defects than those from moduli, the composites manufactured from PCTs seem to profit from the pre-consolidate state already presented by this product before final processing. Finally, it may be noted that any of composites made from pre-impregnated materials 3 der study reached failure 4 the interlaminar shear tests. This fact reveals the high degree of ductility exhibited by these materials which may be relevant for many applications. Thus, the interlaminar shear strength results shown in Tables 13 and 14 correspond to maximum force applied in the test.

Figure 135 ow typical force-displacement curves of the GF/PP composites tested specimens in the short beam shear test, from towpregs, PCT's and TWINTEX ${ }^{\circledR}$. Those curves show that all specimens failed in plastic shear. Therefore, no breaking load could be obtained, which would allow the formal calculation of the interlaminar shear strength. Such results seem to show that a reasonable degree of adhesion between layers was obtained in the composites. Curves also show an obvious different behaviour between samples. While PCT tape and TWINTEX ${ }^{\circledR}$ pultruded composites have similar forcedisplacement behaviour, towpreg based samples showed lower performance. This 6 ostly results from the already mentioned limited degree of impregnation of these samples.

The flexural properties of composite materials under study were compared with those of common use and technical materials, in particular metals, polymers and polymer matrix composites and as $7 \mathrm{u}$ can see in Table 15 [17-22] the results of produced composites bars are higher than traditional materials, revealing a possible growing interest in its application.

\section{Conclusions}

The tests made using a proprietary pultrusion equipment already allow to conclude that is possible to produce, in 8 od conditions, profiles from almost all available thermoplastic matrix pre-impregnated rawmaterials using pull speeds of $0.3 \mathrm{~m} / \mathrm{min}$. Currently, work is carried out to increase the pultrusion processing speed to values in the range from 2 to $6 \mathrm{~m} / \mathrm{min}$. This will equalize the speed of the pultrusion line with that of the towpreg coating and PCT tape production lines. The use of similar operational speeds in both processes (equipments) 9 ill make possible, in future, 10 mbling them in one.

Existing powder-coating equipment was shown to be suitable to produce $\mathrm{CF} / \mathrm{PP}$ and GF/PP towpregs that could be adequately processed into pultruded profiles. From the tests made, the towpregs can be easily and continuously produced at industrial production speeds between 2 a $6 \mathrm{~m} / \mathrm{min}$. 


\section{Page: 11}

T Number: 1

The authors could show their powder coating line as well as their pultrusion line in the manuscript. Reviewer's suggestion was followed (Highlighted in the attached file).

T Number: 2

The authors should explain the potential reasons of this observation here. Why PCTs have a better mechanical prop. than towpreg?

Possible explanation in the text (Highlighted in the attached file).

T Number: 3

which study?

Text modified according to the reviewer's suggestion (Highlighted in the attached file).

T Number: 4

Did the authors get the inter laminar shear failure or tensile failure under 3 point bending set up? It is critical and highly important what kind of failure type was obtained during the experiments. The authors should mention it in the manuscript.

Explained in the text (Highlighted in the attached file).

T Number: 5

shows a

Text modified according to the reviewer's suggestion (Highlighted in the attached file).

T Number: 6

is due to the

Text modified according to the reviewer's suggestion (Highlighted in the attached file).

T Number: 7

it can he ceen

Text modified according to the reviewer's suggestion (Highlighted in the attached file).

T Number: 8

please make it more explicit. What is a good condition?

Explained in text (Highlighted in the attached file).

T Number: $y$

will make it possible or will be possible?

It will be possible (Highlighted in the attached file).

T Number: 10

combining?

Text modified according to the reviewer's suggestion (Highlighted in the attached file). 
It is also worth mentioning that it was possible to produce GF/PP plates by compression moulding from pre-impregnated materials with similar and sometimes 1 1 tter properties than those obtained from

\section{pultruded profiles.}

It was possible to optimize the production of $\mathrm{CF} / \mathrm{PP}$ pultruded profiles and $\mathrm{CF} / \mathrm{PP}$ towpregs, through the use of Taguchi/DOE method, achieving optimal conditions. The addition of the compatibilizing agent (1\% maleic anhydride) did not improve the polymer mass content in towpregs neither the mechanical properties on the final composites.

Three different commercial promising glass fibre reinforced thermoplastic matrix pre-impregnated materials were easily processed by pultrusion and compression moulding: a commercial available GF/PP commingled fibres product and also GF/PP towpregs and tapes manufactured in our own laboratories.

A process window was established for the production of PCT's and towpregs and for the processing of towpregs, PCT's and commingled fibres.

The mechanical properties of the composites processed from all those 2 ree GF/PP pre-impregnated were determined and evaluated. All of them demonstrated to have mechanical properties compatible with the requirements of the major current structural engineering applications. In general, commingled fibres TWINTEX $^{\circledR}$ presented 3 ght better mechanical properties and have shown to be more 4 justed for composite processing than the other pre-impregnated products.

In particular, very good agreement was found between the experimental moduli values of all composites produced and the theoretical ones.

More research must be done in order to increase the processing speeds of CF/PP and GF/PP towpregs as well as PCT's and to improve the impregnation, uniformity and dispersion of raw-materials in the composites.

The mechanical properties obtained in pultruded and 5 mpressed moulded composites allow predicting their adequate use either in general or structural engineering applications. 


\section{Page: 12}

T Number: 1

where is this information in the manuscript?

According to the suggestion, compression molding was removed from the final paper text.

T Number: $\angle$

explicitly mention those three materials here.

Text modified according to the reviewer's suggestion (Highlighted in the attached file).

T Number: 3

slinhtly

SText modified according to the reviewer's suggestion (Highlighted in the attached file).

T Number: 4

What do the authors mean by "adjusted" here? Not clear.

The intention was to write suitable (Highlighted in the attached file).

T Number: $b$

There is no mechanical property information for compression molded composites?

According to the suggestion, compression molding was removed from the final paper text. 


\section{References}

[1] Bechtold G., Wiedmer S., Friedrich K. "Pultrusion of Thermoplastic Composites - New Developments and Modelling Studies", Journal of Thermoplastic Composite Materials, Vol. 15, pp. 443-465, 2002.

[2] Åström T., Carlsson A. "Experimental investigation of pultrusion of glass fibre reinforced polypropylene composites", Composites Part A, 29A, Elsevier, pp. 585-593, 1998.

[3] Miller, A. H., Dodds, N., Hale, J.M., Gibson, A. G. "High Speed pultrusion of thermoplastic matrix composites" Composites Part A, 29A, Elsevier, pp. 773-782, 1998.

[4] Wiedmer. S, Manolesos. M. “An Experimental Study of the Pultrusion of Carbon Fiber-Plyamide 12 Yarn”, Journal of the Thermoplastic Composite Materials, Sage Publications, Vol. 19, pp. 97-112, 2006.

[5] Ramani, K., Borgaonkar, H., Hoyle, C. "Experiments on compression moulding and pultrusion of thermoplastic powder impregnated towpregs”, Composites Manufacturing, 6, Elsevier, pp. 35-43, 1995.

[6] Sala, G., Cutolo, D. "The pultrusion of powder-impreggnated thermoplastic composites", Composites Part A, 28A, Elsevier, pp. 637-646, 1997.

[7] J. F. Silva, J. P. Nunes, F. W. Van-Hattum, C. A Bernardo and A. T. Marques. "Improving Low-Cost Continuous Fibre Thermoplastic Composites by Tailoring Fibre-Matrix Adhesion”. International Workshop on Thermoplastic Matrix Composites, 11-12 September, Gallipoli, Italy, 2003.

[8] P. J. Novo, J. F Silva, J. P. Nunes, F. W. J. van Hattum, A. T. Marques. "Development of a new pultrusion equipment to manufacture thermoplastic matrix composite profiles”, 15th European Conf. on Composite Materials - ECCM 15, June 24-28, Venice, Italy, 2012.

[9] R. F. Silva, J. F. Silva, J. P. Nunes, C. A. Bernardo and A. T. Marques. "New Powder Coating Equipment to Produce Continuous Fibre Thermoplastic Matrix Towpregs". Materials Science Fórum, Vol. 587-588, pp. 246-250, 2008.

[10] Purnima, D., Maiti, S. N., Gupta A. K. "Interfacial adhesion through maleic anhydride grafting of EPDM in PP/EPDM blend”, J. Applied Polymer Science, Vol 102 (6), pp. 5528-5532, 2006.

[11] Oever, M. and Peijs, T. "Continuous-glass-fibre-reinforced polypropylene composites II. Influence of maleic-anhydride modified polypropylene on fatigue behavior", in Composites, Part A:Appl. Sci. and Manufacturing, pp. 227-239, 1998.

[12] Kim, H.-S., Lee, B.-H., Choi, S.-W., Kim, S., Kim, H.-J. “The effect of types of maleic anhydridegrafted polypropylene (MAPP) on the interfacial adhesion properties of bio-flour-filled polypropylene composites", Composites: Part A, Vol. 38, pp. 1473-1482, 2007.

[13] Janevski, A., Bogoeva-Gaceva, G. and Mader. "Characterization of a maleic anhydride-modified polypropylene as an adhesion promoter for glass fiber composites”, J. of Adhesion Science and Technology, Vol. 14 (3), pp. 363-380, 2000.

[14] Nunes, J. P., Silva, J. F. and Marques, A.T. "Using additives to improve the properties of composites made from towpregs”, Proceedings of ANTEC'05, Boston, Massachusetts/USA, May 1-5 (2005).

[15]Fazenda, R., Silva, J. F., Nunes, J. P., Bernardo, C. A. "New Coating Equipment To Produce Long Fibre Thermoplastic Matrix Towpregs at Industrial Scale”, Proceedings of ANTEC'07, Cincinnati, Ohio/USA, May 6-10 (2007).

[16] P. J. Novo, J. P. Nunes, J. F. Silva, V. Tinoco, A. T. Marques. "Production of thermoplastic matrix pre-impregnated materials to manufacture composite pultruded profiles",Ciência e Tecnologia dos Materiais, 25, pp. 84-90, 2013.

[17] K. Van de Velde, P. Kiekens. "Thermoplastic polymers: overview of several properties and their consequences in flax fibre reinforced composites", Polymer Testing, Vol. 20, pp. 885-893, 2001.

[18]Kenneth G Budinski, Michael K. Budinski. "Engineering Materials - Properties and Selection", Pearson Prentice Hall, $8^{\text {th }}$ Edition, 2005.

[19] B. T.Åström. "Manufacturing of Polymer Composites", Nelson Thornes Ltd, $2^{\text {nd }}$ Ed., 2002.

[20] ASM Handbook. "Composites", Vol. 21, ASM International, 2001.

[21]R. J.Crawford. “Plastic Engineering”, Pergamon Press, $2^{\text {nd }}$ Edition, 1990.

[22] Trevor F. Starr. “Pultrusion for Engineers”, CRC Press, 2000. 
This page contains no comments 
Tables

Table 1. Properties of Towpregs and PCT PP raw-materials

Table 2. Properties of Towpregs and PCT fibres raw-materials

\begin{tabular}{|c|c|c|c|c|c|}
\hline \multirow{3}{*}{ Property } & \multicolumn{3}{|c|}{ Glass fibre } & \multirow{2}{*}{\multicolumn{2}{|c|}{$\begin{array}{c}\text { Carbon fibre } \\
\left(\text { TORAY M30 SC }{ }^{\circledR}\right)\end{array}$}} \\
\hline & \multicolumn{2}{|c|}{$\left(305 \mathrm{E}-\mathrm{TYPE} 30^{\circledR}\right)$} & \multirow{2}{*}{$\begin{array}{c}\left.\text { (TufRov } 4599^{\circledR}\right) \\
\text { Manufacturer } \\
\text { datasheet }\end{array}$} & & \\
\hline & $\begin{array}{l}\text { Manufactur } \\
\text { er datasheet }\end{array}$ & $\begin{array}{c}\text { Experimenta } \\
1\end{array}$ & & $\begin{array}{l}\text { Manufacture } \\
\text { r datasheet }\end{array}$ & $\begin{array}{c}\text { Experiment } \\
\text { al }\end{array}$ \\
\hline Linear density (Tex) & 2400 & - & 2400 & 760 & - \\
\hline $\begin{array}{l}\text { Specific gravity } \\
\left(\mathrm{Mg} / \mathrm{m}^{3}\right)\end{array}$ & 2,65 & - & $2,54-2,6$ & 1,73 & - \\
\hline Tensile strength (MPa) & 3500 & 1657 & $1900-2400$ & 5490 & 2731 \\
\hline Young Modulus (GPa) & 76 & 62.5 & 69-76 & 294 & 194.5 \\
\hline Average fibre diameter & 17 & 13.7 & 17 & 5 & 7.37 \\
\hline
\end{tabular}

Table 3. TWINTEX ${ }^{\circledR}$ R PP 60 B 1870 FU from Owens Corning

\begin{tabular}{l|c}
\multicolumn{1}{c|}{ Property } & Values \\
\hline Linear density (Tex) & 1870 \\
Tensile strength (MPa) & 760 \\
Young Modulus (GPa) & 29.5 \\
Fibre mass content (\%) & 60 \\
\hline
\end{tabular}

Table 4. Overview of the main properties of the produced pre-consolidated tapes (PCT's)

\begin{tabular}{l|l|l}
\hline \multicolumn{1}{c|}{ Property } & \multicolumn{1}{|c}{ CF/PP } & \multicolumn{1}{c}{ GF/PP } \\
\hline Fibre type & Carbon, 760 Tex & E-Glass, 2400 Tex \\
Filament diameter & $7 \mu \mathrm{m}$ & $17 \mu \mathrm{m}$ \\
Fibre content & $45 \mathrm{wt} . \%$ & $60 \mathrm{wt} . \%$ \\
Matrix type & Polypropylene (PP) & Polypropylene (PP) \\
Tape width & $25 \mathrm{~mm}$ & $25 \mathrm{~mm}$ \\
Tape linear density & $14000 \mathrm{Tex}$ & $16000 \mathrm{Tex}$ \\
\hline
\end{tabular}


This page contains no comments 
Table 5. Taguchi approach applied to towpregs manufacturing process

\begin{tabular}{c|c|c|c|c}
\hline \multirow{2}{*}{ Experiments } & \multicolumn{3}{|c}{ Table 5. Taguchi approach applied to towpregs manufacturing process } \\
\cline { 2 - 5 } & $\begin{array}{c}\text { Processing variables } \\
\text { Heating oven } \\
\text { temperature } \\
\left({ }^{\mathbf{0}} \mathbf{C}\right)\end{array}$ & $\begin{array}{c}\text { Consolidation furnace } \\
\text { temperature } \\
\left({ }^{\mathbf{0}} \mathbf{C}\right)\end{array}$ & $\begin{array}{c}\text { Linear pulling } \\
\text { speed } \\
(\mathbf{m} / \mathbf{m i n})\end{array}$ & $\begin{array}{c}\text { Polymer mass } \\
\text { fraction } \\
(\%)\end{array}$ \\
\hline 1 & 600 & 350 & 4 & 32.2 \\
2 & 600 & 400 & 6 & 31.4 \\
3 & 600 & 420 & 8 & 20.6 \\
4 & 650 & 350 & 8 & 27.9 \\
5 & 650 & 400 & 4 & 39.9 \\
7 & 650 & 420 & 6 & 40.7 \\
8 & 700 & 350 & 6 & 35.6 \\
9 & 700 & 400 & 8 & 40.6 \\
\end{tabular}

Table 6. Overview of the main properties of the produced Towpregs

\begin{tabular}{l|l|l}
\hline \multicolumn{1}{c|}{ Property } & \multicolumn{1}{|c}{ CF/PP } & \multicolumn{1}{c}{ GF/PP } \\
\hline Fibre type & Carbon, 760 Tex & E-Glass, 2400 Tex \\
Filament diameter & $7 \mu \mathrm{m}$ & $17 \mu \mathrm{m}$ \\
Fibre content & $64,5 \mathrm{wt} . \%$ & $30,7 \mathrm{wt} . \%$ \\
Matrix type & Polypropylene (PP) & Polypropylene (PP) \\
Tape width & $5 \mathrm{~mm}$ & $5 \mathrm{~mm}$ \\
Tape linear density & $1170 \mathrm{Tex}$ & $3465 \mathrm{Tex}$ \\
\hline
\end{tabular}

Table 7. Taguchi approach applied to towpreg processing by pultrusion

\begin{tabular}{c|c|c|c|c|c}
\hline \multirow{2}{*}{ Experiments } & \multicolumn{3}{|c|}{ Processing variables } & \multicolumn{2}{c}{ Bending properties } \\
\cline { 2 - 6 } & $\begin{array}{c}\text { Furnace } \\
\text { temperature } \\
\left({ }^{\circ} \mathbf{C}\right)\end{array}$ & $\begin{array}{c}\text { Heating die } \\
\text { temperature } \\
\left({ }^{\circ} \mathbf{C}\right)\end{array}$ & $\begin{array}{c}\text { Linear } \\
\text { pulling } \\
\text { speed } \\
(\mathbf{m} / \mathbf{m i n})\end{array}$ & $\begin{array}{c}\text { Flexural } \\
\text { modulus } \\
\text { (GPa) }\end{array}$ & $\begin{array}{c}\text { Flexural } \\
\text { strength } \\
\text { (MPa) }\end{array}$ \\
\hline 1 & 160 & 240 & 0.2 & $86.7 \pm 1.3$ & $229.0 \pm 7.3$ \\
\hline 2 & 180 & 240 & 0.2 & $79.5 \pm 2.0$ & $212.4 \pm 12.6$ \\
\hline 3 & 160 & 260 & 0.2 & $91.0 \pm 0.4$ & $241.2 \pm 1.6$ \\
\hline 5 & 180 & 260 & 0.2 & $85.1 \pm 1.7$ & $218.2 \pm 9.1$ \\
\hline 6 & 160 & 240 & 0.3 & $82.1 \pm 2.8$ & $241.7 \pm 13.1$ \\
\hline 7 & 180 & 240 & 0.3 & $87.5 \pm 1.9$ & $239.6 \pm 13.3$ \\
\hline 8 & 160 & 260 & 0.3 & $85.0 \pm 4.4$ & $234.5 \pm 11.5$ \\
\hline
\end{tabular}

Table 8. Taguchi approach applied to towpregs with additive processed

\begin{tabular}{|c|c|c|c|c|c|}
\hline \multirow[b]{2}{*}{ Experiments } & \multicolumn{3}{|c|}{ Processing variables } & \multicolumn{2}{|c|}{ Flexural properties } \\
\hline & $\begin{array}{c}\text { Furnace } \\
\text { temperature } \\
\left({ }^{\circ} \mathrm{C}\right)\end{array}$ & $\begin{array}{l}\text { Heating die } \\
\text { temperature } \\
\left({ }^{\circ} \mathrm{C}\right)\end{array}$ & $\begin{array}{l}\text { Linear } \\
\text { pulling } \\
\text { speed } \\
(\mathrm{m} / \mathrm{min})\end{array}$ & $\begin{array}{l}\text { Flexural } \\
\text { modulus } \\
\text { (GPa) }\end{array}$ & $\begin{array}{c}\text { Flexural } \\
\text { strength } \\
1 \text {.Pa) }\end{array}$ \\
\hline 1 & 160 & 260 & 0.2 & $229.0 \pm 7.3$ & $87.6 \pm 1,3$ \\
\hline 2 & 160 & 240 & 0.2 & $3 \longdiv { 1 . 7 \pm 7 . 8 }$ & $70.4 \pm 2.8$ \\
\hline 3 & 160 & 240 & 0.3 & $437.4 \pm 11.8$ & $80.5 \pm 2.6$ \\
\hline
\end{tabular}




\section{Page: 15}

T Number: 1

This column should switch with the previous column? These are not the strength but the modulus, I guess?

T Number: 2

T Number: 3

T Number: 4 
The material was indicated in the caption of Table 9.

1 hble 9. Flexural test results on composite bars with and without additive

3

5

6

8

10

11

12

13

14

15

16

17

18

19

20

21

22

23

24

25

26

Table 10. Influence of pultrusion conditions on the flexural properties of profiles made from GF/PP

\begin{tabular}{c|c|c|c|c|c|c|c}
\hline \multicolumn{2}{c|}{ Pultrusion conditions } & \multicolumn{2}{c|}{ Flexural properties } & \multicolumn{2}{c|}{ Fibre content } & \multicolumn{2}{c}{$\begin{array}{c}\text { Flexural properties f fibre } \\
\text { volume fraction }\end{array}$} \\
\hline $\begin{array}{c}\text { Pre-heating } \\
\text { temperature }\end{array}$ & $\begin{array}{c}\text { Pultrusion } \\
\text { speed } \\
(\mathrm{m} / \mathrm{min})\end{array}$ & $\begin{array}{c}\text { Modulus } \\
(\mathrm{GPa})\end{array}$ & $\begin{array}{c}\text { Strength } \\
(\mathrm{MPa})\end{array}$ & $\begin{array}{c}\text { Mass } \\
(\%)\end{array}$ & $\begin{array}{c}\text { Volume } \\
(\%)\end{array}$ & $\begin{array}{c}\text { Relative } \\
\text { modulus } \\
(\mathrm{GPa})\end{array}$ & $\begin{array}{c}\text { Relative } \\
3 \\
\text { ength } \\
(\mathrm{MPa})\end{array}$ \\
\hline 170 & 0.2 & $29.1 \pm 0.6$ & $149.2 \pm 14.4$ & 76.1 & 52.2 & $55.7 \pm 1.2$ & $285.2 \pm 27.6$ \\
170 & 0.3 & $28.6 \pm 1.2$ & $142.3 \pm 16.2$ & 75.4 & 51.3 & $55.8 \pm 2.3$ & $255.0 \pm 31.6$ \\
180 & 0.2 & $29.5 \pm 0.1$ & $156.1 \pm 5.1$ & 76.5 & 52.8 & $55.9 \pm 0.2$ & $295.6 \pm 9.7$ \\
180 & 0.3 & $28.6 \pm 0.9$ & $157.7 \pm 12.3$ & 76.0 & 52.1 & $54.9 \pm 1.7$ \\
\hline
\end{tabular}

Table 11. Pultrusion processing parameters for PCT's and Twintex ${ }^{\circledR}$

\begin{tabular}{c|c|c|c|c}
\hline Raw-material & $\begin{array}{c}\text { Heated die } \\
\text { temperature } \\
\left({ }^{\circ} \mathrm{C}\right)\end{array}$ & $\begin{array}{c}\text { Cooled die } \\
\text { temperature } \\
\left({ }^{\circ} \mathrm{C}\right)\end{array}$ & $\begin{array}{c}\text { Pre-heating } \\
\text { temperature } \\
\left({ }^{\circ} \mathrm{C}\right)\end{array}$ & Pulling speed \\
\hline $\mathrm{CF} / \mathrm{PP}$ PCT & 230 & & 160 & 0.2 \\
GF/PP PCT & 230 & 50 & 170 & \\
Twintex ${ }^{\circledR}$ & 300 & & 170 & \\
\hline
\end{tabular}




\section{Page: 16}

T Number: 1

for which material? please indicate in the table caption.

T Number: 2

$\mathrm{MPa}$

T Number: 3

strength 
The meaning of the colors and the scale were added.

1

2

3

4

5

6

7

8

9

10

11

12

13

14

15

16

17

18

19

20

21

22

23

24

25

26

27

28

29

30

31

32

33

34

35

36

37

38

39

40

41

42

43

44

45

46

47

48

49

50

51

52

53

54

55

56

57

58

59

Table 12. Microscope images of GF/PP pultruded 1 ofiles.

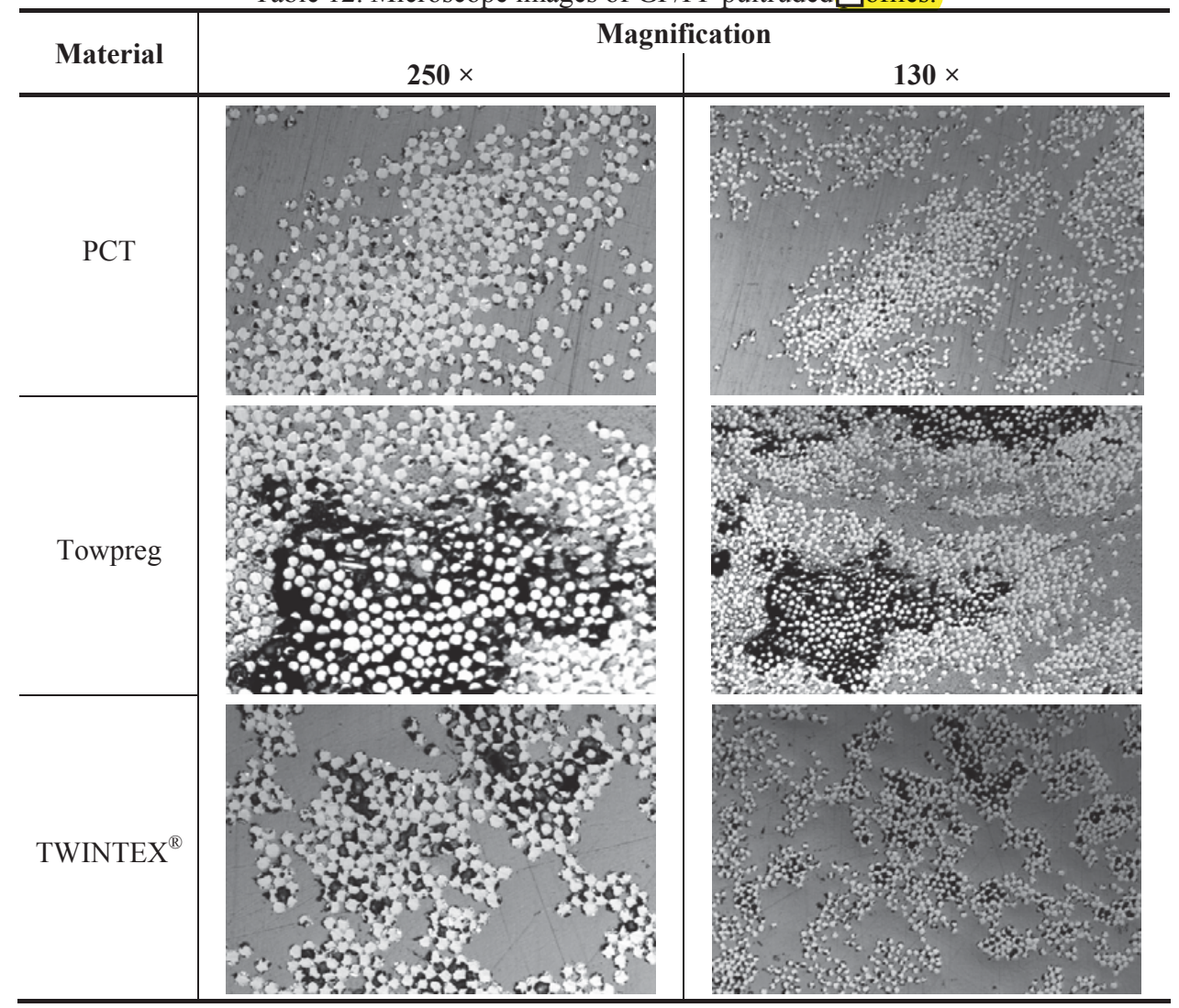

Table 13. CF/PP composite mechanical test results

\begin{tabular}{|c|c|c|c|c|c|}
\hline \multirow{2}{*}{ Test Type } & \multirow{2}{*}{\multicolumn{2}{|c|}{ Property }} & \multicolumn{3}{|c|}{ Pultrusion } \\
\hline & & & \multirow{2}{*}{$\frac{\text { Towpreg }}{90.1 \pm 0.4}$} & \multirow{2}{*}{$\begin{array}{c}\text { Towpreg with } \\
\text { additive }\end{array}$} & \multirow{2}{*}{$\frac{\text { PCT }}{37.7 \pm 2.2}$} \\
\hline \multirow{5}{*}{ Flexural } & \multirow{3}{*}{\multicolumn{2}{|c|}{ 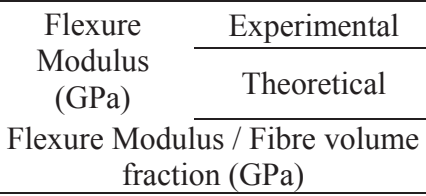 }} & & & \\
\hline & & & 98.9 & 98.7 & 62.7 \\
\hline & & & $178.1 \pm 0.8$ & $173.5 \pm 2.6$ & $118.2 \pm 6.9$ \\
\hline & $\begin{array}{c}\text { Flexure } \\
\text { Strength } \\
\text { (MPa) }\end{array}$ & Experimental & $241.2 \pm 1.6$ & $229.0 \pm 7.3$ & $158.7 \pm 4.2$ \\
\hline & \multicolumn{2}{|c|}{$\begin{array}{c}\text { Flexure Strength / Fibre volume } \\
\text { fraction }(\mathrm{MPa})\end{array}$} & $476.7 \pm 3.2$ & $453.5 \pm 14.5$ & $497.5 \pm 13.2$ \\
\hline \multirow{5}{*}{ Tensile } & \multirow{3}{*}{\multicolumn{2}{|c|}{\begin{tabular}{cc} 
Tensile & Experimental \\
\cline { 2 - 2 } $\begin{array}{c}\text { Modulus } \\
(\mathrm{GPa})\end{array}$ & Theoretical \\
\\
$\begin{array}{c}\text { Tensile Modulus / Fibre volume } \\
\text { fraction }(\mathrm{GPa})\end{array}$
\end{tabular}}} & $110.6 \pm 5.9$ & $106.1 \pm 6.3$ & $63.5 \pm 4.3$ \\
\hline & & & 98.9 & 98.7 & 62.7 \\
\hline & & & $218.6 \pm 11.7$ & $210.1 \pm 12.5$ & $199.1 \pm 13.5$ \\
\hline & $\begin{array}{c}\text { Tensile } \\
\text { Strength } \\
(\mathrm{MPa})\end{array}$ & Experimental & $1060.8 \pm 43.1$ & $1129.3 \pm 34.6$ & $636.9 \pm 38.4$ \\
\hline & \multicolumn{2}{|c|}{$\begin{array}{l}\text { Tensile Strength / Fibre volume } \\
\text { fraction }(\mathrm{MPa})\end{array}$} & $2096.4 \pm 85.2$ & $2236.2 \pm 68.5$ & $1996.6 \pm 120.4$ \\
\hline $\begin{array}{l}\text { Inter- } \\
\text { laminar } \\
\text { Shear }\end{array}$ & \multicolumn{2}{|c|}{$\begin{array}{l}\text { Interlaminar Shear Strength } \\
\qquad(\mathrm{MPa})\end{array}$} & $12.3 \pm 0.3$ & $13.0 \pm 0.4$ & $14.0 \pm 0.2$ \\
\hline \multicolumn{3}{|c|}{ Fibre volume fraction $(\%)$} & 50.6 & 50.5 & 31.9 \\
\hline
\end{tabular}




\section{Page: 17}

T Number: 1

Please indicate the scale of the plots in $\mathrm{mm}$ or micrometer.

Also indicate what is black, what is gray and white standing for? Is there any defect, void, dry spot in the figures? 
Table 14. Test results on the processed GF/PP composites

\begin{tabular}{|c|c|c|c|c|c|}
\hline \multirow{2}{*}{$\begin{array}{l}\text { Test } \\
\text { Type }\end{array}$} & \multirow{2}{*}{\multicolumn{2}{|c|}{ Property }} & \multicolumn{3}{|c|}{ Pultrusion } \\
\hline & & & $\begin{array}{l}\text { Commingled } \\
\text { fibres }\end{array}$ & Towpregs & PCT \\
\hline \multirow{5}{*}{ Flexural } & \multirow{2}{*}{$\begin{array}{l}\text { Flexure Modulus } \\
\qquad(\mathrm{GPa})\end{array}$} & Experimental & $26.2 \pm 2.0$ & $28.6 \pm 0.9$ & $16.8 \pm 1.5$ \\
\hline & & Theoretical & 23.8 & 33.1 & 19.1 \\
\hline & \multicolumn{2}{|c|}{$\begin{array}{c}\text { Flexure Modulus / Fibre volume } \\
\text { fraction (GPa) }\end{array}$} & $70.6 \pm 5.4$ & $54.9 \pm 1.7$ & $56.0 \pm 5.0$ \\
\hline & $\begin{array}{c}\text { Flexure Strength } \\
(\mathrm{MPa})\end{array}$ & Experimental & $595.0 \pm 24$ & $158.0 \pm 12.3$ & $329.0 \pm 30$ \\
\hline & $\begin{array}{r}\text { Flexure Strength } \\
\text { fraction }\end{array}$ & $\begin{array}{l}\text { Fibre volume } \\
\mathrm{MPa})\end{array}$ & $1603.8 \pm 64.7$ & $303.3 \pm 23.6$ & $1096.7 \pm 100$ \\
\hline \multirow{5}{*}{ Tensile } & \multirow{2}{*}{$\begin{array}{l}\text { Tensile Modulus } \\
\text { (GPa) }\end{array}$} & Experimental & $24.9 \pm 1.1$ & $33.9 \pm 1.5$ & $21.4 \pm 1.5$ \\
\hline & & Theoretical & 23.8 & 33.1 & 19.1 \\
\hline & \multicolumn{2}{|c|}{$\begin{array}{c}\text { Tensile Modulus / Fibre volume } \\
\text { fraction }(\mathrm{GPa})\end{array}$} & $67.1 \pm 3.0$ & $63.5 \pm 2.9$ & $71.3 \pm 5.0$ \\
\hline & $\begin{array}{l}\text { Tensile Strength } \\
\qquad(\mathrm{MPa})\end{array}$ & Experimental & $545.9 \pm 31.7$ & $>336.3 \pm 22.3$ & $355.8 \pm 53.2$ \\
\hline & \multicolumn{2}{|c|}{$\begin{array}{c}\text { Tensile Strength / Fibre volume } \\
\text { fraction }(\mathrm{MPa})\end{array}$} & $1471.4 \pm 85.4$ & $>645.5 \pm 42.8$ & $1186.0 \pm 177.3$ \\
\hline $\begin{array}{l}\text { Inter- } \\
\text { laminar } \\
\text { Shear }\end{array}$ & \multicolumn{2}{|c|}{ Interlaminar Shear Strength (MPa) } & $26.8 \pm 1.7$ & $7.5 \pm 0.1$ & $27.8 \pm 0.6$ \\
\hline \multicolumn{3}{|c|}{ Fibre volume fraction $(\%)$} & 37.1 & 52.1 & 30.0 \\
\hline
\end{tabular}

Table 15. Compared the flexural properties of composite materials under study with those of common use and technical materials

\begin{tabular}{|c|c|c|c|c|c|c|}
\hline \multirow{2}{*}{ Material } & \multirow{2}{*}{$\begin{array}{l}\text { Density } \\
\left(\mathrm{kg} / \mathrm{m}^{3}\right)\end{array}$} & Corrected & Corrected & \multicolumn{2}{|c|}{ xural properties } & \multirow[b]{2}{*}{$\begin{array}{c}\text { Modulus }^{1 / 2} / \text { Density } \\
(\mathrm{GPa})^{1 / 2} /\left(\mathrm{Mg} / \mathrm{m}^{3}\right)\end{array}$} \\
\hline & & 1 enght & $\begin{array}{c}\text { Specific } 2 \text { enght } \\
(\mathrm{kN} * \mathrm{~m} / \mathrm{kg})\end{array}$ & $\begin{array}{l}\text { Modulus } \\
\text { (GPa) }\end{array}$ & $\begin{array}{l}\text { Specific modulus } \\
\text { (MN*m/Kg) }\end{array}$ & \\
\hline $\mathrm{CF} / \mathrm{PP}$ (from towpreg)[66\%] $]^{\mathrm{a})}$ & 1322.5 & 241.2 & 182.4 & 90.1 & 68.1 & 7.2 \\
\hline GF/PP (from towpreg)[76\%] $]^{a)}$ & 1767.3 & 158.0 & 89.4 & 28.6 & 16.1 & 3.0 \\
\hline GF/PP (from Twintex ${ }^{(\mathrm{B})}$ )[63\%] $]^{\mathrm{a})}$ & 1519.0 & 595.0 & 391.7 & 26.2 & 17.2 & 3.4 \\
\hline $\begin{array}{l}\text { CF/Epoxy laminate (from } \\
\text { prepeg hand layup - AS4 } \\
\text { continuos tows) }[74 \%]^{a)}\end{array}$ & 1560.0 & 1724.0 & 1105.1 & 134.0 & 85.9 & 7.4 \\
\hline Kevlar/Epoxy UD & 1360.0 & 655.0 & 481.6 & 67.0 & 49.2 & 6.0 \\
\hline $\begin{array}{l}\text { GF/PP compression molded } \\
\text { (from UD melt-impregnated } \\
\text { prepegs) [60\%] }{ }^{\text {a) }}\end{array}$ & 1480.0 & 570.0 & 385.1 & 22.0 & 14.9 & 3.2 \\
\hline GF Pultrusion [60-80\%] $]^{\mathrm{a})}$ & $\begin{array}{l}2016.0- \\
2288.0\end{array}$ & $345.0-552.0$ & $171.1-241.3$ & $31.0-41.0^{\mathrm{e})}$ & $15.3-17.9$ & $2.8-3.2$ \\
\hline Stainless steel $(304)^{b)}$ & 8000.0 & $517.0^{\mathrm{dl}}$ & 64.6 & $193.0^{\mathrm{e})}$ & 24.1 & 1.7 \\
\hline Carbon Steel $(1020)^{b)}$ & 7870.0 & $400.0^{\mathrm{d})}$ & 50.8 & $206.0^{\mathrm{e})}$ & 26.2 & 1.8 \\
\hline Aluminium alloy $(5052-\mathrm{H} 34)^{c)}$ & 2680.0 & $262.0^{\mathrm{d})}$ & 97.8 & $70.0^{\mathrm{e})}$ & 26.1 & 3.1 \\
\hline Aluminium alloy $(3003-\mathrm{H} 14)^{c)}$ & 2730.0 & $152.0^{\mathrm{d})}$ & 55.6 & $69.0^{\mathrm{e})}$ & 25.2 & 3.0 \\
\hline Aluminium $(1100)^{b)}$ & 2710.0 & $90.0^{d)}$ & 33.2 & $69.0^{\mathrm{e})}$ & 25.5 & 3.1 \\
\hline Epoxy & 1150.0 & $110.0-115.0$ & $95.7-100$ & $3.0-3.2$ & $2.6-2.8$ & $1.5-1.6$ \\
\hline Polyester & 1200.0 & $80.0-123.0$ & $66.7-102.5$ & $3.0-3.5$ & 2.9 & 1.5 \\
\hline PEEK & 1292.0 & 110.2 & 85.2 & $3.9-2.8$ & $2.2-3.0$ & 1.4 \\
\hline PPS & 1350.0 & $96.0-151.0$ & 71.1-111.9 & $3.4-4.1$ & $2.5-3.0$ & $1.4-1.5$ \\
\hline PA-6 & 1115.0 & $69.0-117.3$ & $61.8-105.2$ & $1.9-2.8$ & $1.7-2.5$ & $1.2-1.5$ \\
\hline PC & 1215.0 & $81.4-93.2$ & $66.9-76.7$ & $2.1-2.4$ & $1.8-2.0$ & $1.2-1.3$ \\
\hline PP & 909.5 & $44.8-55.2$ & $49.3-60.7$ & $0.8-1.7$ & $0.9-1.7$ & $1.0-1.4$ \\
\hline
\end{tabular}

a) Fibre mass content; b) Annealed; c) At temper; d)Tensile Strength; e) Tensile Modulus 
Page: 18

T Number: 1 strength

T) Number: 2

strength 
Figures
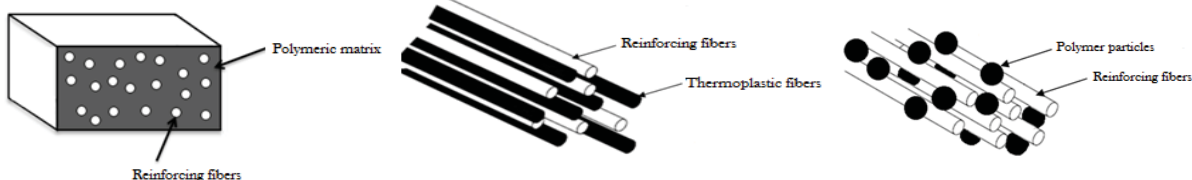

a) Pre-consolidate tapes (PCTs) b) Commingled fibres

Figure 1. Pre-impregnated products under study

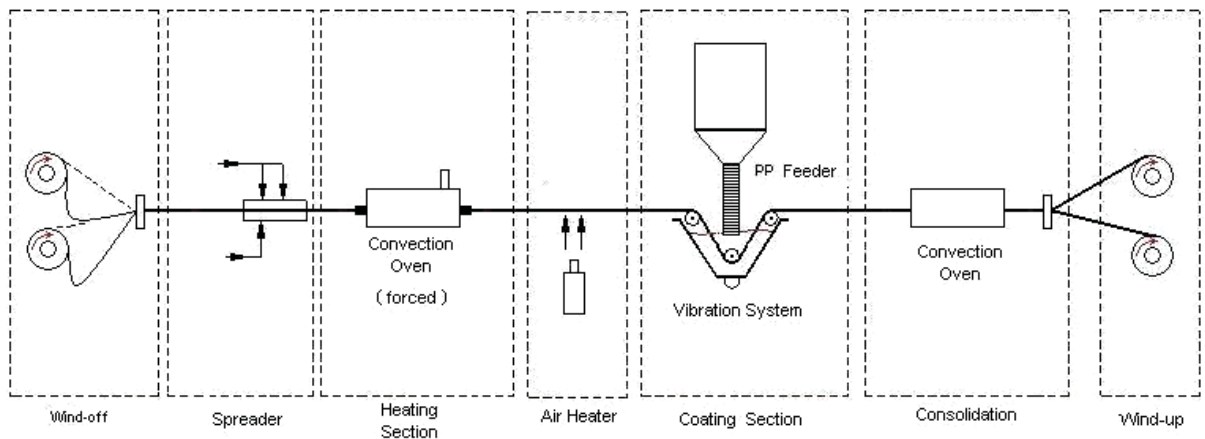

Figure 2. Powder coating line setup.

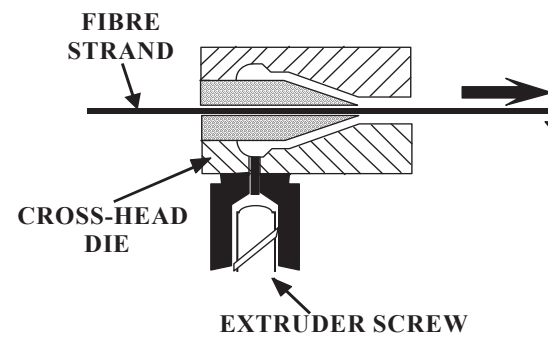

Figure 3. Cross-head extrusion die

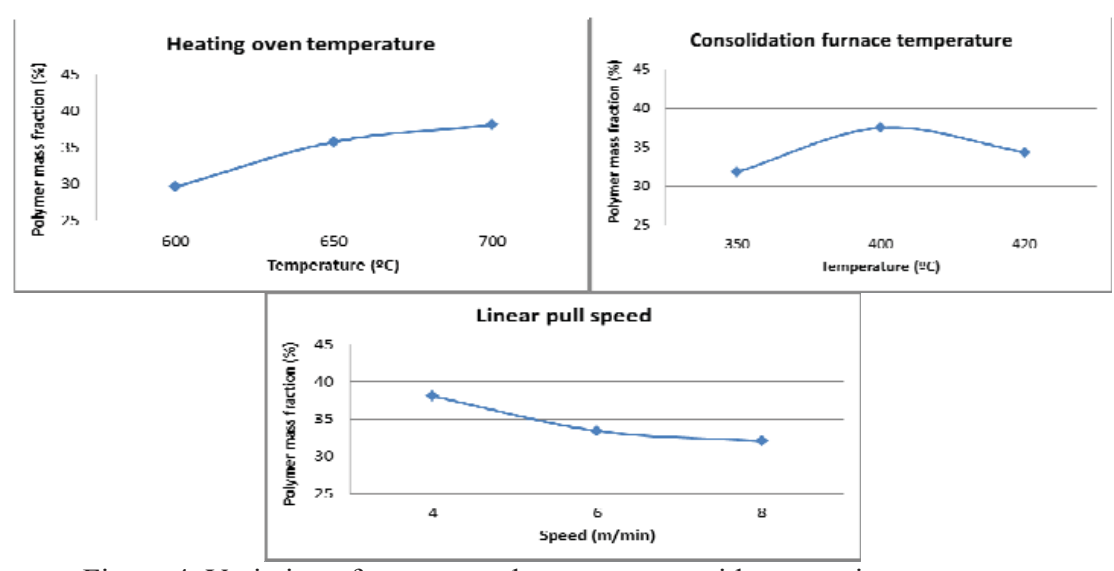

Figure 4. Variation of towpreg polymer content with processing parameters

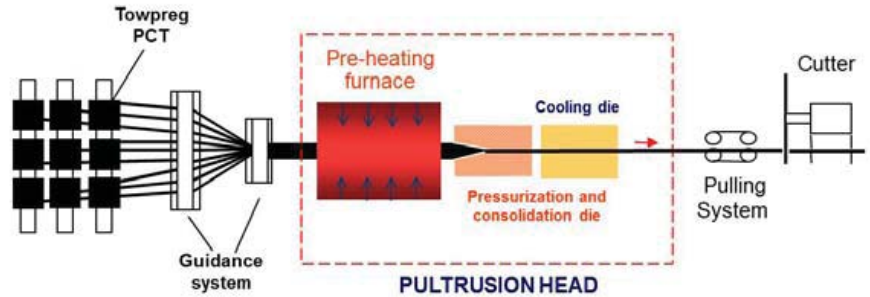

Figure 5. Schematic diagram of the pultrusion line 
This page contains no comments 


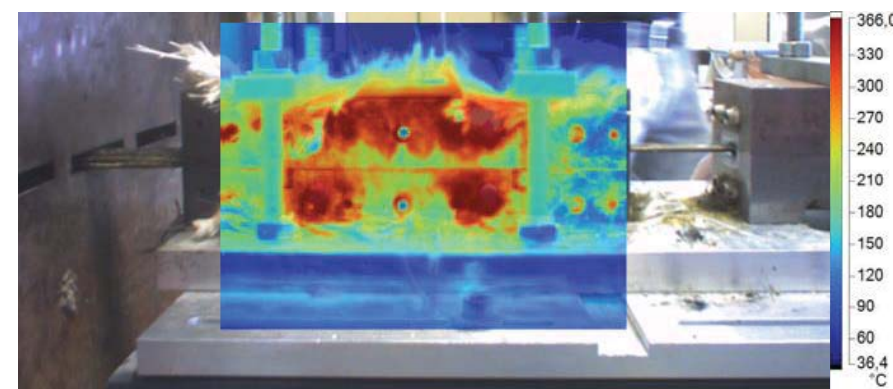

Figure 6. Heated die temperature distribution profile

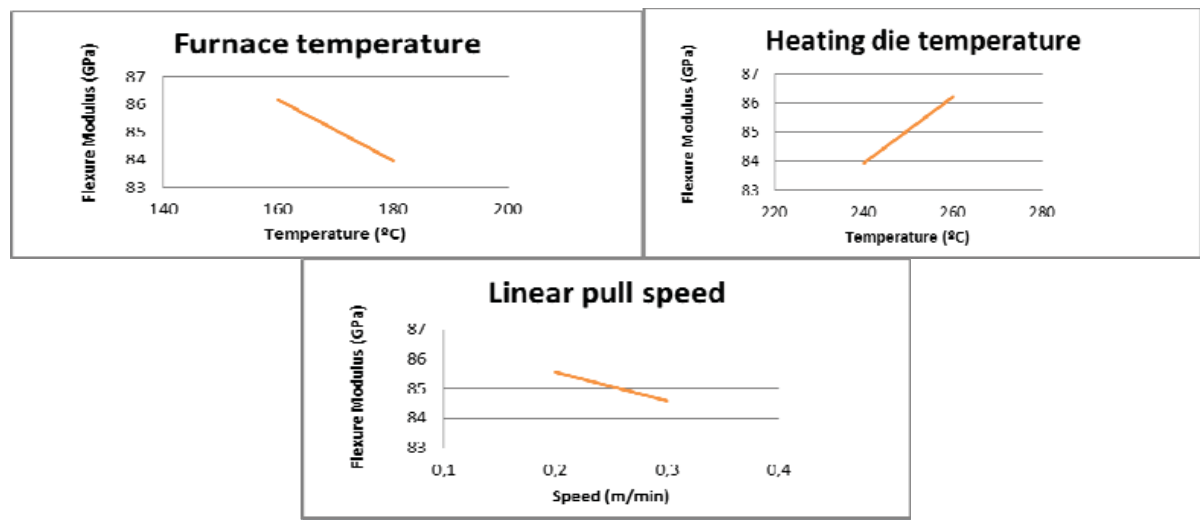

Figure 7. Variation of the flexural modulus with the selected processing parameters
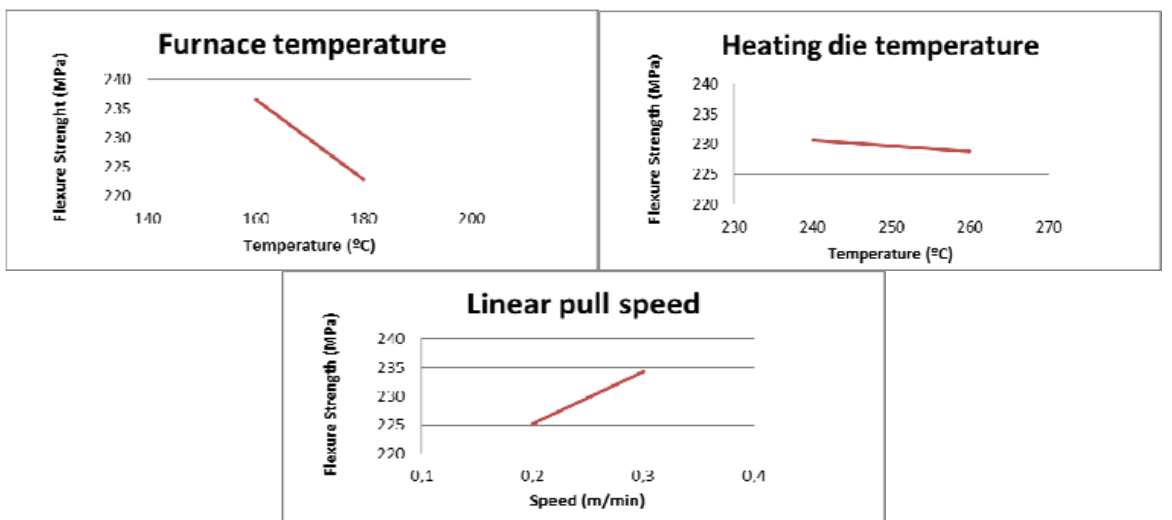

Figure 8. Variation of the flexural strength with the selected processing parameters

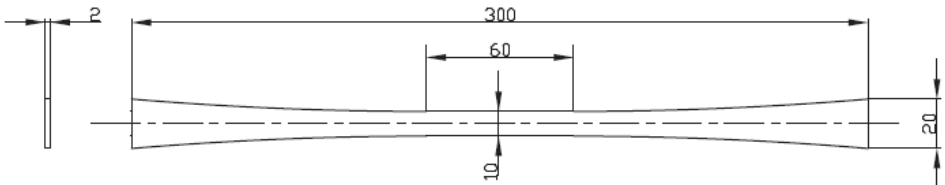

Figure 9. Geometry of the tensile test specimens
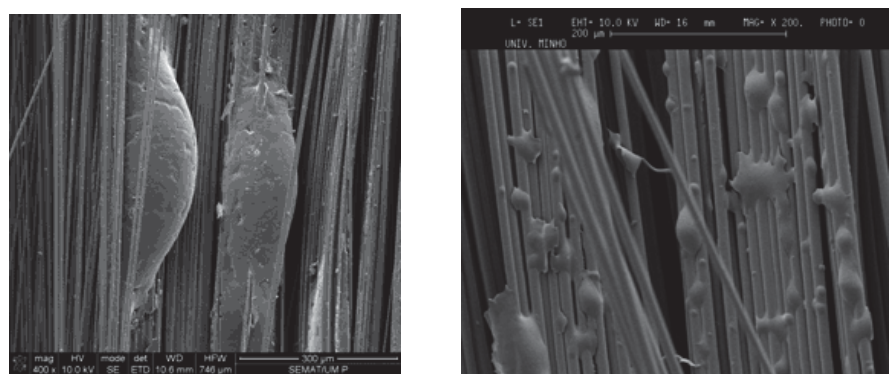

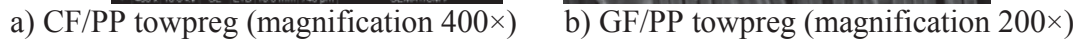

Figure 10. Typical CF/PP and GF/PP towpreg SEM micrographs 
This page contains no comments 
Towpreg with additive

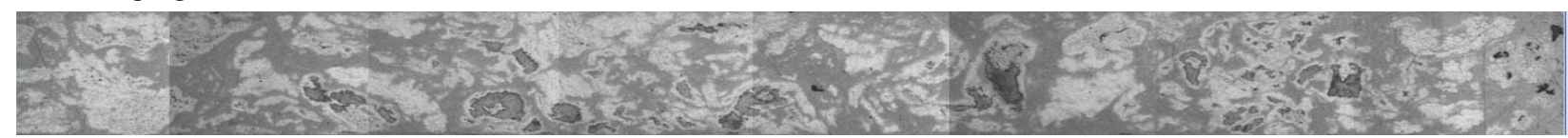

PCT

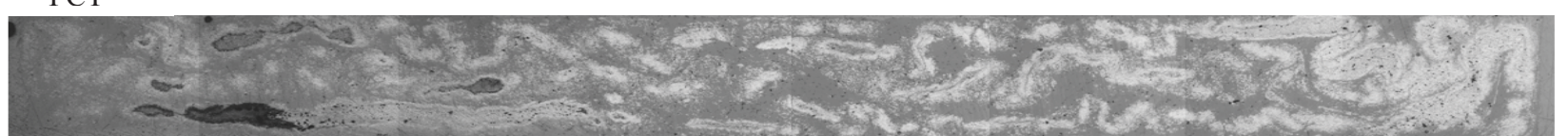

Carbon fibres impregnated with polypropylene;

Polypropylene matrix;

Dry carbon fibres;

1 ffects. Corrected

Figure 11. Optical micrographs of the CF/PP pultruded profiles cross-sections 2 hagnification of $8.75 \times$ )

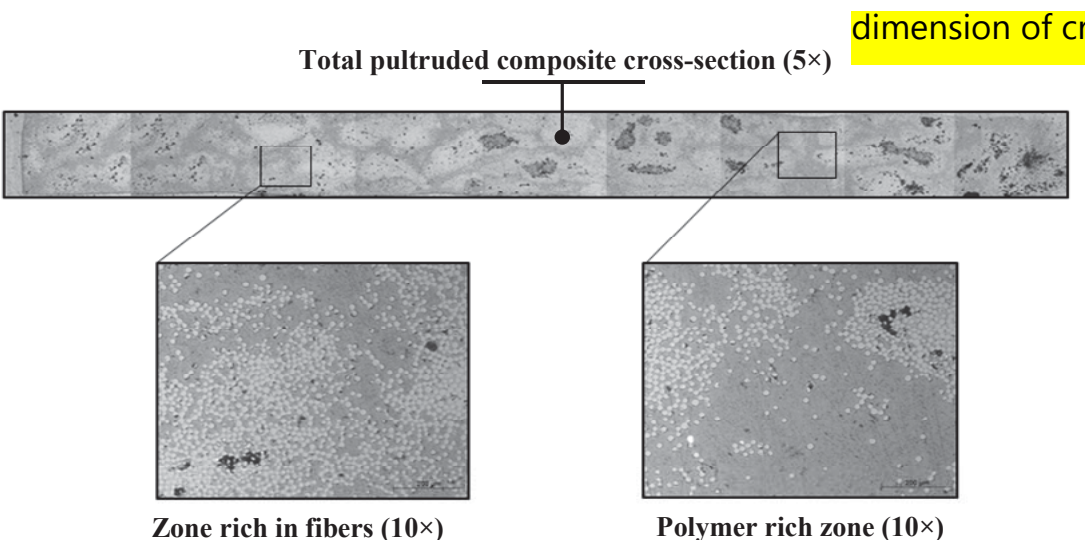

Figure 12. Cross-section of pultruded profiles from GF/PP towpregs observed under 3 tical microscopy dimension of cross-section added

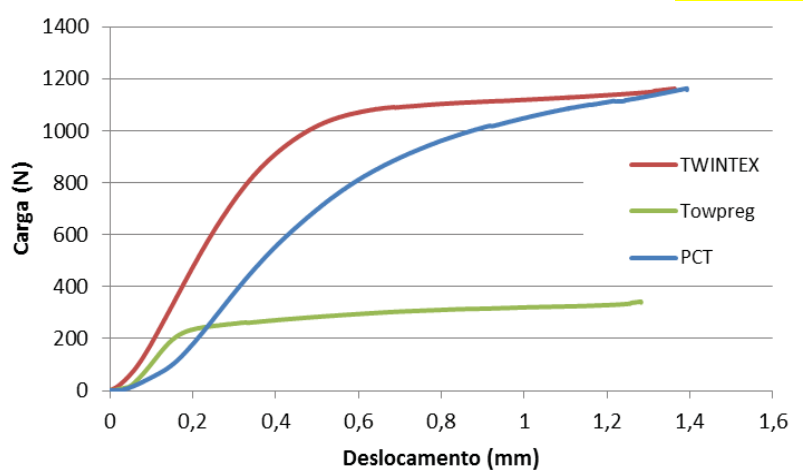

4 gure 13. Short beam test results of pultruded composites from GF/PP pre-impregnated materials

\section{Corrected}




\section{Page: 21}

T Number: 1

what kind of defect? void, porosity? please specify.

T Number: 2

Please indicate the scale of the graphs on the figure.

T Number: 3

Please show the dimensions on the cross section. I presume it is $20 \times 2 \mathrm{~mm}$.

T Number: 4

Please use the axis titles in English! 


\title{
PULTRUSION OF FIBRE REINFORCED THERMOPLASTIC PRE-IMPREGNATED MATERIALS
}

\author{
$\underline{\text { P. J. Novo }}^{1 *}$, J F. Silva $^{2}$, J. P. Nunes ${ }^{3}$ and A. T. Marques ${ }^{4}$ \\ ${ }^{1}$ Dep. of Mechanical Engineering, ESTG, Polytechnic Institute of Leiria, 2411-901 Leiria, \\ Portugal \\ ${ }^{2}$ Dep. of Mechanical Engineering, ISEP, 4200-072 Porto, Portugal \\ ${ }^{3}$ Institute of Polymers and Composites/I3N, Minho University, 4800-058 Guimaraes, Portugal \\ ${ }^{4}$ DEMEGI / FEUP, 4200-465 Porto, Portugal \\ * Corresponding author (e-mail: pnovo@ estg.ipleiria.pt)
}

Keywords: towpreg; PCT; pre-impregnated materials; pultrusion; thermoplastic composite; mechanical properties

\begin{abstract}
Fibre reinforced thermoplastic pre-impregnated materials produced continuously by diverse methods and processing conditions were used to produce composites using pultrusion. The processing windows used to produce these materials and composites profiles were optimized by using the Taguchi / DOE (Design of Experiments) methods. Those composites were then submitted to mechanical testing and microscopy analysis. The obtained results were compared with the expected theoretical ones predicted from the Rule Of Mixtures (ROM) and with those of similar engineering conventional available materials. The results obtained shown that produced composites have adequate properties for applications in common and structural engineering markets.
\end{abstract}




\section{Introduction}

Although only recently thermoplastic matrices have been used in long and continuous fibre reinforced

composites as alternative to thermosetting matrices, the number of their applications is increasing due to their better ecological and mechanical performance [1]. Composites with thermoplastic matrices offer increased fracture toughness, higher damage tolerance, short processing cycle times and excellent environmental stability. They are recyclable, post-formable and can be joined by welding. The use of long/continuous fibre reinforced thermoplastic matrix composites involves, however, great technological and scientific challenges since thermoplastics present much higher viscosity than thermosettings, which makes much difficult and complex the impregnation of reinforcements and consolidation tasks [1-6].

Today, two major technologies are being used to allow wet reinforcing fibres with thermoplastic polymers [1, 4-6]: i) the direct melting of the polymer and, ii) the intimate fibre/matrix contact prior to final composite fabrication. Continuous fibre reinforced thermoplastic matrix pre-impregnated tapes (PCT's) are, for example, produced by direct melting processes. Alternatively, intimate contact processes allow producing cheap and promising pre-impregnated materials, such as, commingled fibres and powder coated towpregs. Sometimes, thermoplastic compatibilizers are added to the matrices to improve their adhesion and facilitate impregnation to reinforcements [7].

This work studies and compares the processability of final composite parts by using three different pre-impregnated materials produced by each one of the above mentioned wetting techniques. One is a pre-consolidated tape (Fig. 1 a)) that was produced by the melting process (cross-head extrusion) [8]. From the other two produced by fibre/matrix intimate contact methods, one is a commercially available commingled fibres product (Fig. 1 b) and the other a towpreg (Fig. 1 c)) produced by our own developed dry coating line [9]. All studied pre-impregnated materials were based on a continuous carbon and glass fibres reinforced polypropylene matrix system. Pultrusion was the selected manufacturing method for processing all these pre-impregnated materials into composite parts. It is a versatile continuous high speed production technology, allowing the production of fibre reinforced complex profiles. Nowadays crucial challenges in pultrusion such as the residual stresses in the product which may induce damage or premature cracks and delamination are being studied [10-12].

The optimization of the pultrusion process was made by studying the influence of the most relevant processing parameters in the final properties of the produced pre-impregnated materials and composites. The method of Taguchi / DOE (Design of Experiments) was used to achieve this aim.

The possibility of using maleic anhydride as compatibilizer of carbon and glass fibre reinforced polypropylene composites was also analysed in the present work. 
Towpregs were characterized by scanning electron microscopy (SEM), visual analysis and their polymer mass contents were determined. The final composite parts were also submitted to tensile, interlaminar and flexural tests, as well as calcination and optical microscopy tests and the results were compared with theoretical ones that can be predicted by using the ROM (Rule Of Mixtures) and other engineering traditional materials (steel, aluminium and several polymers).

\section{Experimental}

\subsection{Raw Materials}

The following raw materials were used to produce carbon reinforced polypropylene (CF/PP) pre-impregnated materials for this work: i) a PP powder ICORENE 9184B $\mathrm{P}^{\circledR}$ and carbon fibre roving M30 SC ${ }^{\circledR}$ from the ICO Polymers and TORAY, respectively, were used to produce the CF/PP towpregs, ii) PP powder Moplen RP348U ${ }^{\circledR}$ from Basell and the carbon fibre roving already mentioned were used to manufacture the CF/PP PCT tapes.

For the glass reinforced polypropylene (GF/PP) towpregs, a 2400 Tex type E fibre rovings from Owens Corning and Icorene ${ }^{\circledR}$ 9184B P polypropylene from ICO Polymers France were used. Also, the GF/PP PCT tapes were manufactured with glass fibres (TufRov 4599) from PPG Industries and a polypropylene matrix (Moplen RP348U) from Basell.

Commercial commingled GF/PP fibres TWINTEX® R PP 60 B 1870 FU from Owens Corning were also used in the production of pultrusion thermoplastic composite profiles, as reference of a current commercially available pre-impregnated product.

Some batches of CF/PP and GF/PP towpregs were also produced using PP powder (ICORENE 9184B $\mathrm{P}^{\circledR}$ ) blended with 1\% in mass content of maleic anhydride S $4729608707^{\circledR}$ from Merck Schuchardt OHG, in order to assess the possible enhancement of fibre/matrix adhesion [13-16].

Tables 1 and 2 summarise relevant properties of the polypropylene, glass and carbon fibres used in present work to produce pre-impregnated raw materials (towpregs and PCT's). Table 3 shows the manufacturer datasheets properties of TWINTEX ${ }^{\circledR}$.

\subsection{Production of Thermoplastic Matrix Pre-Impregnated Products}

The dry powder coating equipment used to produce fibre reinforced towpregs is depicted in Figure 2 $[9,17]$.

The pre-consolidated tapes (PCT's) used in this work were produced in a cross-head extrusion equipment (see Fig.3) from our own laboratories [8]. Using this equipment, it was possible to produce the tapes (PCT's) pre-impregnated raw-materials. The overview of their main properties is given in Table 4. 


\subsubsection{CF/PP towpregs production and optimization}

In order to optimize the production of CF/PP powder coated towpregs, different processing variables combinations were experimented and the number of trials optimized using the Taguchi approach. The studied operational parameters were:

- heating oven temperature $\left(600,650\right.$ and $\left.700{ }^{\circ} \mathrm{C}\right)$; consolidation oven temperature $\left(350,400\right.$ and $\left.450{ }^{\circ} \mathrm{C}\right)$; linear pull speed (4, 6 and $8 \mathrm{~m} / \mathrm{min})$.

The Taguchi approach was applied to the towpregs production process in order to obtain the condition that maximizes polymer powder content.

The polymer mass fraction in the towpregs, $\omega_{p}$, was determined by weighting towpreg strips produced in those different conditions, using equation 1:

$$
\omega_{p}=\frac{W_{t}-W_{f}}{W_{t}}
$$

where $W_{t}$ and $W_{f}$ are the measured unit length weights of the towpreg strip and fibre roving, respectively.

Table 5 shows the used processing conditions and obtained results, according to the established design of experiments. The average polymer mass content in towpregs, established by the design of experiences was $34.5 \%$ (Table 5).

In Figure 4 an average plot is obtained by plotting the average polymer mass fraction effect against the corresponding main processing variables (temperatures/linear pull speed) levels.

The optimal condition obtained from Taguchi method application led to the following operating parameters selection: heating oven temperature and consolidation oven temperatures of $700{ }^{\circ} \mathrm{C}$ and $400^{\circ} \mathrm{C}$ respectively, and a linear pulling speed of $6 \mathrm{~m} / \mathrm{min}$. Using this optimal operative condition, the amount of polymer should increase up to $45.6 \%$. However, it was found that the average polymer content in continuous towpreg production was only $40.0 \%$ (enough for the of use of towpregs in the pultrusion process, where a limit value of polymer mass content of $22 \%$ should be achieved as minimum, if only rovings are used [18]). Also, the addition of $1 \%$ of maleic anhydride to the PP polymer had no influence on the towpreg polymer mass fraction. Table 6 summarizes the determined properties on towpregs produced using the optimal combination of parameters.

\subsubsection{GF/PP towpregs production and optimization}

To try maximizing the polymer powder content in the towpregs the following processing conditions were varied within the next ranges: i) convective oven temperature $\left({ }^{\circ} \mathrm{C}\right): 650$ - 700; ii) Consolidation furnace temperature $\left({ }^{\circ} \mathrm{C}\right): 350-450$; iii) Coating line pulling speed $(\mathrm{m} / \mathrm{min}): 4-6$.

From the polymer mass fractions obtained in produced towpreg strips it was possible to establish as optimal the following operating parameters: convective and consolidation oven temperatures of $700{ }^{\circ} \mathrm{C}$ 
and $400^{\circ} \mathrm{C}$ respectively, and a linear pulling speed of $6 \mathrm{~m} / \mathrm{min}$. In such operational conditions the GF/PP towpregs were continuously produced with polymer mass content of $30.7 \%$.

Unexpectedly, very low polymer mass fractions ( $10 \%-16 \%)$ were obtained when PP powder with $1 \%$ of maleic anhydride was used to produce GF/PP towpregs. Hence, the idea of using this additive to improve adhesion of the PP matrix to the glass fibres was abandoned. Table 6 summarizes the determined towpreg properties obtained with the combination of selected parameters.

\subsection{Pultrusion of pre-impregnated materials}

The towpregs, PCT's and commingled fibres were processed into composite rectangular bar profiles using the laboratorial pultrusion line, Figure $5[8,19]$.

To produce composite profiles, the pre-impregnated materials are guided into the pre-heating furnace to be heated up to the required temperature. Then, they enter in the pultrusion heated die to be heated and consolidated to the required size and, after cooled down in the cooling die to solidify. The control of the die temperatures was made using two PT 100 sensors, one in each half-die. The die temperature distribution profile, obtained with a FLUKE TI45FT infrared camera, can be seen in Figure 6.

In this work, it was designed and manufactured a die to allow producing a $20 \times 2 \mathrm{~mm}^{2}$ bar-shaped profile.

\subsubsection{Towpreg processing}

$\mathrm{CF} / \mathrm{PP}$ towpregs were manufactured by pultrusion into composite bar profiles using the most relevant operating conditions. The Taguchi's/DOE method was applied, maintaining the cooling die at $25^{\circ} \mathrm{C}$, in order to optimize the processing parameters:

i) furnace temperature $\left(160\right.$ or $\left.180^{\circ} \mathrm{C}\right)$; ii) heating die temperature $\left(240\right.$ or $\left.260^{\circ} \mathrm{C}\right)$; iii)linear pull-speed $(0.2$ or $0.3 \mathrm{~m} / \mathrm{min})$.

Results have shown that it was not possible to produce pultruded profiles from towpregs in steady conditions at linear pull-speeds and consolidation die temperatures higher than $0.4 \mathrm{~m} / \mathrm{min}$ and $260{ }^{\circ} \mathrm{C}$, respectively. By using higher values for those two parameters, the process became unsteady, mainly due to the thermoplastic polymer reflux at the entrance of the consolidation die and also to their accumulation at the entrance of the cooling die.

Table 7 summarizes the processing conditions according to established in the design of experiments. The variations of the flexural modulus and strength (determined according to the procedure described in paragraph 2.4.2) with the selected processing parameters, needed for achieving the optimal condition, can be seen in Figures 7 and 8 . 
The optimal condition concerning flexural stiffness maximization obtained from Taguchi method application led to the following operating parameters selection: furnace and heated die oven temperatures strength the obtained parameters combination were: furnace and heated die oven temperatures of $160{ }^{\circ} \mathrm{C}$ and $240^{\circ} \mathrm{C}$ respectively, and a linear pulling speed of $0.3 \mathrm{~m} / \mathrm{min}$.

It is possible to observe that the furnace temperature of $160^{\circ} \mathrm{C}$ lead to the better results. That could be explained by the lower polymer reflux on the entrance of the heated die. The optimal operating conditions to maximize both flexural properties were: furnace and heated die oven temperatures of $160{ }^{\circ} \mathrm{C}$ and $260^{\circ} \mathrm{C}$ respectively, and a linear pulling speed of $0.2 \mathrm{~m} / \mathrm{min}$.

Finally, towpregs with additive were also pultruded into composite bars using the condition that optimizes both flexural properties (Table 8, experiment 1) and two other experiments (Table 8, experiments 2 and 3). The results from flexural testing shown in Table 9 allow concluding that the use of such additive had no significant influence on the flexural properties.

GF/PP pre-impregnated towpreg rovings were processed by pultrusion into rectangular $20 \times 2\left(\mathrm{~mm}^{2}\right)$ profiles. To determine the best processing window, the main processing conditions were varied,

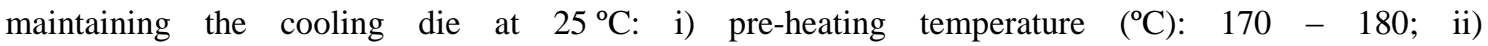
pressurization/consolidation die temperature $\left({ }^{\circ} \mathrm{C}\right): 240-300$; iii) linear pultrusion speed (m/min): 0.2 0.4 .

Results have shown that it was not possible to produce, in steady conditions, profiles from towpregs at pultrusion speeds and pressurization/consolidation die temperatures higher than $0.3 \mathrm{~m} / \mathrm{min}$ and $280{ }^{\circ} \mathrm{C}$, respectively. By using higher, values the process became unsteady as it was already found for CF/PP towpregs processing. The same problems also occurred for temperatures below $270^{\circ} \mathrm{C}$ in the pressurization/consolidation die. By maintaining constant the temperatures in the cooling and pressurization/consolidation dies at $25^{\circ} \mathrm{C}$ and $280^{\circ} \mathrm{C}$, respectively, profiles pultruded in different processing conditions were submitted to the flexural tests (see 2.5.2). As it is seen in Table 10, very similar values of flexural moduli and strengths were found by using pre-heating furnace temperatures and linear pultrusion pulling speeds in the ranges of $170-180\left({ }^{\circ} \mathrm{C}\right)$ and $0.2-0.3 \mathrm{~m} / \mathrm{min}$, respectively. While the slower pultrusion pulling speed of $0.2 \mathrm{~m} / \mathrm{min}$ seemed to generate profiles with higher absolute values, this was not confirmed by the flexural properties divided by the determined fibre volume fraction depicted in two last the columns of Table 10. On the other hand, higher flexural strength values were obtained at the higher temperature of $180^{\circ} \mathrm{C}$ in pre-heating furnace, even if flexural strength relative values were considered (ratio between the flexural strength and the fibre volume fraction). Hence, it was concluded that the GF/PP towpreg pultrusion operating window should be the following one: i) pre- 
heating temperature $\left({ }^{\circ} \mathrm{C}\right): 170-180$; ii) pressurization/consolidation die temperature $\left({ }^{\circ} \mathrm{C}\right): 280$; iii) cooling die temperature $\left({ }^{\circ} \mathrm{C}\right): 25$; iv) linear pultrusion speed $(\mathrm{m} / \mathrm{min}): 0.2-0.3$.

\subsubsection{Pre-consolidate tapes $\left(\mathrm{PCT}^{\prime} \mathrm{s}\right)$ and Twintex ${ }^{\circledR}$ processing}

PCT's and Twintex ${ }^{\circledR}$ were processed into rectangular $20 \times 2\left(\mathrm{~mm}^{2}\right)$ bar using the already mentioned pultrusion equipment being operating conditions shown in Table 11.

\subsection{Testing}

\subsubsection{Microscopy analysis}

$\mathrm{CF} / \mathrm{PP}$ and GF/PP towpreg samples were characterized by scanning electron microscopy (SEM) to evaluate the adhesion of the polymer powder to the fibres and its distribution. In order to prevent charge build-up by electron absorbed by the samples, those were coated with a layer of gold with approximately $6.5 \mu \mathrm{m}$ thick, before the observation.

To determine the impregnation quality and to evaluate the fibre distribution and fibre/matrix adhesion of the thermoplastic composites, their cross-sections were studied under optical microscopy. Observations were done using reflected light optical microscopy (Olympus BH-2). A digital camera (Leica DFC200) was used to get the image cross sectional views of the samples.

\subsubsection{Mechanical testing}

Bar samples were submitted to flexural, tensile and interlaminar testing according to the ISO standards 14125, 527 and 14130, respectively. The mechanical properties obtained were compared to the theoretical ones predicted by using the Rule of Mixtures (ROM).

Tensile tests were conducted, according to ISO 527, in a $100 \mathrm{kN}$ universal testing machine at the crosshead speed of $2 \mathrm{~mm} / \mathrm{min}$ using $180 \times 20 \times 2 \mathrm{~mm}^{3}$ rectangular samples. The tensile modulus was determined from the slope of the initial linear portion of the experimental stress/strain curve. A SG Shimadzu ${ }^{\circledR} 50 \mathrm{~mm}$ length strain-gauge was used up to $0.3 \%$ strain, for accurate determination of the tensile modulus. Regarding the determination of tensile strength, it was not possible to proceed with the test until specimen failure due to grip slippage. Hence, new specimen geometry (see Figure 9) was designed and tested with good results, allowing determining the samples tensile strengths.

Three-point flexural tests were also conducted on five $100 \times 20 \times 2\left(\mathrm{~mm}^{3}\right)$ composite specimens, using $100 \mathrm{kN}$ universal testing machine and a distance between supports of $80 \mathrm{~mm}$, according to ISO 14125 , at a crosshead speed of $1 \mathrm{~mm} / \mathrm{min}$.

Samples with dimensions of $20 \times 20 \times 2\left(\mathrm{~mm}^{3}\right)$, cut from composites processed from each preimpregnated raw material, were submitted to interlaminar shear tests according to ISO 14130. These three point bending tests were conducted in a $50 \mathrm{kN}$ universal testing machine by using an initial pre-load of $1 \mathrm{~N}$ at the crosshead speed of $1 \mathrm{~mm} / \mathrm{min}$ and a $10 \mathrm{~mm}$ span between supports. 


\subsubsection{Calcination testing}

Carbon and glass fibre composites mass content was determined by using calcination tests according

to the EN ISO 1172. Composite samples, weighting approximately $2 \mathrm{~g}$, were submitted to calcination inside a crucible in a muffle furnace during $10 \mathrm{~min}$ at $620^{\circ} \mathrm{C}$

\section{Results and Discussion}

Figure 10 shows SEM micrographs of CF/PP and GF/PP towpregs samples. A good degree of adhesion between both carbon and glass fibres and the polymer powder particles was obtained. Also, a reasonable polymer powder distribution on the fibres was achieved at the optimised operating conditions.

The cross-sections of the pultruded composites were studied under optical Microscopy. As can be seen from Figure 11, all CF/PP composite profiles from towpregs (with and without additive) and PCT's have a reasonable distribution of the reinforcing fibres over the cross-sections. However, large differences in impregnation quality occur between the different samples that are likely to be related, directly, to the impregnation state of pre-impregnated materials used in pultrusion. It may be seen that the impregnation quality of the PCT composite samples is good, presenting almost all fibres completely surrounded ('wetout') by the polymer. Only a few large dry spots were observed. This is most likely due to the good degree of impregnation already achieved in the PCT raw-material tape prior to the pultrusion step.

The samples from CF/PP towpreg with additive show a higher quantity of dry zones than the ones without additive. This could be due to some lack of compatibility between the fibre sizing and the used maleic anhydride coupling agent.

As Figure 12 shows, it was still possible to distinguish discontinuities on the cross section of pultruded composites from GF/PP towpregs, where it may be seen zones very rich in polymer contrasting with others with much higher quantity of fibres.

The microscopy images taken from the samples of the pultruded composites using GF/PP PCT, TWINTEX $^{\circledR}$ and GF/PP towpreg, are given in Table 12. All pre-impregnated materials lead to a reasonable distribution of the reinforcing fibres over the cross-sections, although small improvements in fibre distribution can be observed going from PCT through TWINTEX ${ }^{\circledR}$ to towpreg composites. A good fibre distribution means that the fibres are uniformly spread on the polymeric matrix, without significant agglomeration areas.

It may be seen that the impregnation quality of the PCT composite samples is excellent, presenting almost all fibres completely surrounded ('wet-out') by the polymer, hardly showing any dry spots in the pultruded samples.

The TWINTEX $^{\circledR}$-based samples also show a very good impregnation of the fibre. This is likely due to the intimate contact between the individual dry glass and PP fibres prior to the final pultrusion stage, 
making very small the effective remaining impregnation distance between polypropylene and glass fibres which leads to an easier consolidation. However, some larger dry spots were observed between the glass fibres at larger magnifications (see Table 12), showing an overall impregnation quality poor when compared with the one observed in the PCT tape based pultruded composites. Finally, the depicted towpreg-based composite samples exhibit larger apparent dry zones. This is most likely due to the uneven distribution of the dry polymer powder in the towpreg, prior to pultrusion. It seems to be harder to bridge the large distances of dry glass fibre during pultrusion, which results on bigger unimpregnated zones in the pultruded composites.

Tables 13 and 14 summarize all experimentally results obtained from the CF/PP and GF/PP unidirectional composites processed by pultrusion, from the pre-impregnated products under study. To better evaluate and compare the mechanical properties obtained on the composites processed from the different pre-impregnated products studied, Tables 13 and 14 also present theoretical expected values and relative values of specific properties.

The theoretical values of moduli, $E$, were directly obtained from the rule of mixtures using the rawmaterial properties presented in Tables 1, 2 and 3, following the Eq. 2:

$$
E=E_{f} \cdot v_{f}+E_{p} \cdot\left(1-v_{f}\right)
$$

where, $E_{f}, E_{p}$ and $v_{p}$ are the fibre modulus, polymer modulus and fibre volume fraction, respectively.

As can be seen from Tables 13 and 14, the experimental moduli obtained from de CF/PP and GF/PP composites are in good agreement with the predicted theoretical ones. Some experimental values are even higher than the theoretical expected ones. This can be explained considering that the volume fraction content of some samples can be higher than the determined by the calcination tests.

Using the proposed new geometry (Figure 9) for the tensile test specimens, it was possible to reach failure loads and therefore determine their tensile strengths.

Analysing Table 13, one can conclude that composites processed from the CF/PP PCT's demonstrated to have better flexural and interlaminar shear strengths than those produced from CF/PP towpregs. From Table 14, it is possible to conclude that commingled fibres (TWINTEX ${ }^{\circledR}$ ) presented, in general, better properties and had also shown to be more adjusted to commercial application demands and to be easily processed into final composites by the currently used manufacturing methods, probably due to their easy consolidation.

In any case, worse flexural strength and modulus results were found in GF/PP towpreg and GF/PP PCT's pultruded composites, respectively, when compared to TWINTEX ${ }^{\circledR}$. These lower results obtained in the flexural tests are probably consequence of the inferior degree of impregnation observed in the 
towpreg based composites and, in the case of GF/PP PCT's based composites, result from the higher rich polymer regions exhibited by this material in its outside layers, decreasing the flexural properties.

Nevertheless, the GF/PP pre-impregnated products produced in our laboratories (towpregs and PCTs) have already demonstrated very good mechanical behaviour, namely, in terms of stiffness. In fact, the composites manufactured from these products presented experimental moduli values very closed to the theoretical expected ones. While composites processed from the PCTs demonstrated to have better mechanical strength, those produced from towpregs presented higher moduli. However, if the fibre volume fractions were considered, then the relative moduli (flexure modulus/fibre volume fraction) of PCT's and towpregs exhibit similar values. As mechanical strength values are more affected by small defects than those from moduli, the composites manufactured from PCTs seem to profit from the preconsolidate state already presented by this product before final processing. Finally, it may be noted that none of the composites made from pre-impregnated materials reached failure in the three point bending interlaminar shear tests. This fact reveals the high degree of ductility exhibited by these materials which may be relevant for many applications. Thus, the interlaminar shear strength results shown in Tables 13 and 14 correspond to maximum force applied in the test.

Figure 13 shows a typical force-displacement curves of the GF/PP composites tested specimens in the short beam shear test, from towpregs, PCT’s and TWINTEX ${ }^{\circledR}$. Those curves show that all specimens failed in plastic shear. Therefore, no breaking load could be obtained, which would allow the formal calculation of the interlaminar shear strength. Such results seem to show that a reasonable degree of adhesion between layers was obtained in the composites. Curves also show an obvious different behaviour between samples. While PCT tape and TWINTEX ${ }^{\circledR}$ pultruded composites have similar forcedisplacement behaviour, towpreg based samples showed lower performance. This is due to the results from the already mentioned limited degree of impregnation of these samples.

The flexural properties of composite materials under study were compared with those of common use and technical materials, in particular metals, polymers and polymer matrix composites and as it can be seen in Table 15 [20-25] the results of produced composites bars are higher than traditional materials, revealing a possible growing interest in its application.

\section{Conclusions}

The tests made using a proprietary pultrusion equipment already allow to conclude that is possible to produce, without major production problems, profiles from almost all available thermoplastic matrix pre-impregnated raw-materials using pull speeds of $0.3 \mathrm{~m} / \mathrm{min}$. Currently, work is carried out to increase the pultrusion processing speed to values in the range from 2 to $6 \mathrm{~m} / \mathrm{min}$. This will equalize the speed of 
the pultrusion line with that of the towpreg coating and PCT tape production lines. With the use of similar operational speeds in both processes (equipments) it will be possible, in future, combining them in one.

Existing powder-coating equipment was shown to be suitable to produce CF/PP and GF/PP towpregs that could be adequately processed into pultruded profiles. From the tests made, the towpregs can be easily and continuously produced at industrial production speeds between 2 a $6 \mathrm{~m} / \mathrm{min}$.

It was possible to optimize the production of $\mathrm{CF} / \mathrm{PP}$ pultruded profiles and $\mathrm{CF} / \mathrm{PP}$ towpregs, through the use of Taguchi/DOE method, achieving optimal conditions. The addition of the compatibilizing agent (1\% maleic anhydride) did not improve the polymer mass content in towpregs neither the mechanical properties on the final composites.

Three different commercial promising glass fibre reinforced thermoplastic matrix pre-impregnated materials were easily processed by pultrusion: a commercial available GF/PP commingled fibres product and also GF/PP towpregs and tapes manufactured in our own laboratories.

A process window was established for the production of PCT's and towpregs and for the processing of towpregs, PCT's and commingled fibres.

The mechanical properties of the composites processed from all those three GF/PP pre-impregnated (TWINTEX $^{\circledR}$, towpregs and PCT's) were determined and evaluated. All of them demonstrated to have mechanical properties compatible with the requirements of the major current structural engineering applications. In general, commingled fibres TWINTEX $^{\circledR}$ presented slightly better mechanical properties and have shown to be more suitable for composite processing than the other pre-impregnated products.

In particular, very good agreement was found between the experimental moduli values of all composites produced and the theoretical ones.

More research must be done in order to increase the processing speeds of CF/PP and GF/PP towpregs as well as PCT's and to improve the impregnation, uniformity and dispersion of raw-materials in the composites.

The mechanical properties obtained in the pultruded composites allow predicting their adequate use either in general or structural engineering applications. 


\section{References}

[1] Wiedmer. S, Manolesos. M. “An Experimental Study of the Pultrusion of Carbon Fiber-Plyamide 12 Yarn", Journal of the Thermoplastic Composite Materials, Sage Publications, Vol. 19, pp. 97-112, 2006.

[2] Åström T., Carlsson A. "Experimental investigation of pultrusion of glass fibre reinforced polypropylene composites", Composites Part A, 29A, Elsevier, pp. 585-593, 1998.

[3] Miller, A. H., Dodds, N., Hale, J.M., Gibson, A. G. "High Speed pultrusion of thermoplastic matrix composites” Composites Part A, 29A, Elsevier, pp. 773-782, 1998.

[4] Bechtold G., Wiedmer S., Friedrich K. "Pultrusion of Thermoplastic Composites - New Developments and Modelling Studies", Journal of Thermoplastic Composite Materials, Vol. 15, pp. 443-465, 2002.

[5] Ramani, K., Borgaonkar, H., Hoyle, C. "Experiments on compression moulding and pultrusion of thermoplastic powder impregnated towpregs", Composites Manufacturing, 6, Elsevier, pp. 35-43, 1995.

[6] Sala, G., Cutolo, D. "The pultrusion of powder-impreggnated thermoplastic composites", Composites Part A, 28A, Elsevier, pp. 637-646, 1997.

[7] J. F. Silva, J. P. Nunes, F. W. Van-Hattum, C. A Bernardo and A. T. Marques. "Improving Low-Cost Continuous Fibre Thermoplastic Composites by Tailoring Fibre-Matrix Adhesion". International Workshop on Thermoplastic Matrix Composites, 11-12 September, Gallipoli, Italy, 2003.

[8] P. J. Novo, J. F Silva, J. P. Nunes, F. W. J. van Hattum, A. T. Marques. "Development of a new pultrusion equipment to manufacture thermoplastic matrix composite profiles”, 15th European Conf. on Composite Materials - ECCM 15, June 24-28, Venice, Italy, 2012.

[9] R. F. Silva, J. F. Silva, J. P. Nunes, C. A. Bernardo and A. T. Marques. "New Powder Coating Equipment to Produce Continuous Fibre Thermoplastic Matrix Towpregs". Materials Science Fórum, Vol. 587-588, pp. 246-250, 2008.

[10] Baran I, Tutum CC, Nielsen MW, Hattel JH. Process induced residual stresses and distortions in pultrusion. Compos Part B: Eng 2013; 51:148-161.

[11]Baran I, Akkerman R, Hattel JH. Modelling the pultrusion process of an industrial L-shaped composite profile. Composite Structures 2014; 118:37-48.

[12] Baran I, Hattel JH, Akkerman. Investigation of process induced warpage for pultrusion of a rectangular hollow profile. Composites Part B: Engineering 2015; 68:365-374.

[13] Purnima, D., Maiti, S. N., Gupta A. K. "Interfacial adhesion through maleic anhydride grafting of EPDM in PP/EPDM blend”, J. Applied Polymer Science, Vol 102 (6), pp. 5528-5532, 2006.

[14] Kim, H.-S., Lee, B.-H., Choi, S.-W., Kim, S., Kim, H.-J. "The effect of types of maleic anhydridegrafted polypropylene (MAPP) on the interfacial adhesion properties of bio-flour-filled polypropylene composites”, Composites: Part A, Vol. 38, pp. 1473-1482, 2007.

[15] Janevski, A., Bogoeva-Gaceva, G. and Mader. "Characterization of a maleic anhydride-modified polypropylene as an adhesion promoter for glass fiber composites", J. of Adhesion Science and Technology, Vol. 14 (3), pp. 363-380, 2000.

[16] Nunes, J. P., Silva, J. F. and Marques, A.T. "Using additives to improve the properties of composites made from towpregs”, Proceedings of ANTEC'05, Boston, Massachusetts/USA, May 1-5 (2005).

[17] Fazenda, R., Silva, J. F., Nunes, J. P., Bernardo, C. A. "New Coating Equipment To Produce Long Fibre Thermoplastic Matrix Towpregs at Industrial Scale”, Proceedings of ANTEC'07, Cincinnati, Ohio/USA, May 6-10 (2007).

[18] S. T. Peters. "Handbook of Composites", Springer, $2^{\text {nd }}$ Edition, 1997.

[19] P. J. Novo, J. P. Nunes, J. F. Silva, V. Tinoco, A. T. Marques. "Production of thermoplastic matrix pre-impregnated materials to manufacture composite pultruded profiles", Ciência e Tecnologia dos Materiais, 25, pp. 84-90, 2013.

[20] K. Van de Velde, P. Kiekens. "Thermoplastic polymers: overview of several properties and their consequences in flax fibre reinforced composites”, Polymer Testing, Vol. 20, pp. 885-893, 2001.

[21] Kenneth G Budinski, Michael K. Budinski. "Engineering Materials - Properties and Selection”, Pearson Prentice Hall, $8^{\text {th }}$ Edition, 2005.

[22] B. T.Åström. “Manufacturing of Polymer Composites”, Nelson Thornes Ltd, $2^{\text {nd }}$ Ed., 2002.

[23] ASM Handbook. "Composites”, Vol. 21, ASM International, 2001.

[24] R. J.Crawford. “Plastic Engineering”, Pergamon Press, $2^{\text {nd }}$ Edition, 1990.

[25] Trevor F. Starr. "Pultrusion for Engineers", CRC Press, 2000. 
Tables

Table 1. Properties of Towpregs and PCT PP raw-materials

Table 2. Properties of Towpregs and PCT fibres raw-materials

\begin{tabular}{|c|c|c|c|c|c|}
\hline \multirow{3}{*}{ Property } & \multicolumn{3}{|c|}{ Glass fibre } & \multirow{2}{*}{\multicolumn{2}{|c|}{$\begin{array}{c}\text { Carbon fibre } \\
\left(\text { TORAY M30 SC }{ }^{\circledR} \text { ) }\right.\end{array}$}} \\
\hline & \multicolumn{2}{|c|}{$\left(305 E-T Y P E ~ 30^{\circledR}\right)$} & \multirow{2}{*}{$\begin{array}{c}\left.\text { (TufRov } 4599^{\circledR}\right) \\
\text { Manufacturer } \\
\text { datasheet }\end{array}$} & & \\
\hline & $\begin{array}{l}\text { Manufactur } \\
\text { er datasheet }\end{array}$ & $\begin{array}{c}\text { Experimenta } \\
1\end{array}$ & & $\begin{array}{c}\text { Manufacture } \\
\text { r datasheet }\end{array}$ & $\begin{array}{c}\text { Experiment } \\
\text { al }\end{array}$ \\
\hline Linear density (Tex) & 2400 & - & 2400 & 760 & - \\
\hline $\begin{array}{l}\text { Specific gravity } \\
\left(\mathrm{Mg} / \mathrm{m}^{3}\right)\end{array}$ & 2,65 & - & $2,54-2,6$ & 1,73 & - \\
\hline Tensile strength $(\mathrm{MPa})$ & 3500 & 1657 & $1900-2400$ & 5490 & 2731 \\
\hline Young Modulus (GPa) & 76 & 62.5 & $69-76$ & 294 & 194.5 \\
\hline Average fibre diameter & 17 & 13.7 & 17 & 5 & 7.37 \\
\hline
\end{tabular}

Table 3. TWINTEX ${ }^{\circledR}$ R PP 60 B 1870 FU from Owens Corning

\begin{tabular}{l|c}
\multicolumn{1}{c|}{ Property } & Values \\
\hline Linear density (Tex) & 1870 \\
Tensile strength (MPa) & 760 \\
Young Modulus $(\mathrm{GPa})$ & 29.5 \\
Fibre mass content $(\%)$ & 60 \\
\hline
\end{tabular}

Table 4. Overview of the main properties of the produced pre-consolidated tapes (PCT's)

\begin{tabular}{l|l|l}
\hline \multicolumn{1}{c|}{ Property } & \multicolumn{1}{c}{ CF/PP } & \multicolumn{1}{c}{ GF/PP } \\
\hline Fibre type & Carbon, 760 Tex & E-Glass, 2400 Tex \\
Filament diameter & $7 \mu \mathrm{m}$ & $17 \mu \mathrm{m}$ \\
Fibre content & $45 \mathrm{wt} . \%$ & $60 \mathrm{wt} \%$ \\
Matrix type & Polypropylene (PP) & Polypropylene (PP) \\
Tape width & $25 \mathrm{~mm}$ & $25 \mathrm{~mm}$ \\
Tape linear density & $14000 \mathrm{Tex}$ & $16000 \mathrm{Tex}$ \\
\hline
\end{tabular}


Table 5. Taguchi approach applied to towpregs manufacturing process

\begin{tabular}{|c|c|c|c|c|}
\hline \multirow[b]{2}{*}{ Experiments } & \multicolumn{3}{|c|}{ Processing variables } & \multirow{2}{*}{$\begin{array}{c}\text { Results } \\
\text { Polymer mass } \\
\text { fraction } \\
(\%)\end{array}$} \\
\hline & $\begin{array}{l}\text { Heating oven } \\
\text { temperature } \\
\left({ }^{\circ} \mathrm{C}\right)\end{array}$ & $\begin{array}{c}\text { Consolidation furnace } \\
\text { temperature } \\
\left({ }^{\circ} \mathrm{C}\right)\end{array}$ & $\begin{array}{c}\text { Linear pulling } \\
\text { speed } \\
(\mathbf{m} / \mathbf{m i n})\end{array}$ & \\
\hline 1 & 600 & 350 & 4 & 32.2 \\
\hline 2 & 600 & 400 & 6 & 31.4 \\
\hline 3 & 600 & 420 & 8 & 20.6 \\
\hline 4 & 650 & 350 & 8 & 27.9 \\
\hline 5 & 650 & 400 & 4 & 39.9 \\
\hline 6 & 650 & 420 & 6 & 40.7 \\
\hline 7 & 700 & 350 & 6 & 35.6 \\
\hline 8 & 700 & 400 & 8 & 40.6 \\
\hline 9 & 700 & 420 & 4 & 40.4 \\
\hline & & & Average & 34.5 \\
\hline
\end{tabular}

Table 6. Overview of the main properties of towpregs produced using the optimal condition

\begin{tabular}{l|l|l}
\hline \multicolumn{1}{c|}{ Property } & \multicolumn{1}{|c}{ CF/PP } & \multicolumn{1}{c}{ GF/PP } \\
\hline Fibre type & Carbon, 760 Tex & E-Glass, 2400 Tex \\
Filament diameter & $7 \mu \mathrm{m}$ & $17 \mu \mathrm{m}$ \\
Fibre content & $60.0 \mathrm{wt} . \%$ & $69.3 \mathrm{wt} . \%$ \\
Matrix type & Polypropylene (PP) & Polypropylene (PP) \\
Tape width & $5 \mathrm{~mm}$ & $5 \mathrm{~mm}$ \\
Tape linear density & $1270 \mathrm{Tex}$ & $3460 \mathrm{Tex}$ \\
\hline
\end{tabular}

Table 7. Taguchi approach applied to towpreg processing by pultrusion

\begin{tabular}{c|c|c|c|c|c}
\hline \multirow{2}{*}{ Experiments } & \multicolumn{3}{|c|}{ Processing variables } & \multicolumn{2}{c}{ Bending properties } \\
\cline { 2 - 6 } & $\begin{array}{c}\text { Furnace } \\
\text { temperature } \\
\left({ }^{\mathbf{O}} \mathbf{C}\right)\end{array}$ & $\begin{array}{c}\text { Heating die } \\
\text { temperature } \\
\left({ }^{\circ} \mathbf{C}\right)\end{array}$ & $\begin{array}{c}\text { Linear } \\
\text { pulling } \\
\text { speed } \\
(\mathbf{m} / \mathbf{m i n})\end{array}$ & $\begin{array}{c}\text { Flexural } \\
\text { modulus } \\
(\mathbf{G P a})\end{array}$ & $\begin{array}{c}\text { Flexural } \\
\text { strength } \\
(\mathbf{M P a})\end{array}$ \\
\hline 1 & 160 & 240 & 0.2 & $86.7 \pm 1.3$ & $229.0 \pm 7.3$ \\
\hline 2 & 180 & 240 & 0.2 & $79.5 \pm 2.0$ & $212.4 \pm 12.6$ \\
\hline 3 & 160 & 260 & 0.2 & $91.0 \pm 0.4$ & $241.2 \pm 1.6$ \\
\hline 4 & 180 & 260 & 0.2 & $85.1 \pm 1.7$ & $218.2 \pm 9.1$ \\
\hline 5 & 160 & 240 & 0.3 & $82.1 \pm 2.8$ & $241.7 \pm 13.1$ \\
\hline 6 & 180 & 240 & 0.3 & $87.5 \pm 1.9$ & $239.6 \pm 13.3$ \\
\hline 7 & 160 & 260 & 0.3 & $85.0 \pm 4.4$ & $234.5 \pm 11.5$ \\
\hline 8 & 180 & 260 & 0.3 & $83.7 \pm 2.8$ & $221.3 \pm 7.1$ \\
\hline
\end{tabular}

Table 8. Taguchi approach applied to towpregs processed with additive

\begin{tabular}{c|c|c|c|c|c}
\hline \multirow{2}{*}{ Experiments } & \multicolumn{3}{|c|}{ Processing variables } & \multicolumn{2}{c}{ Flexural properties } \\
\cline { 2 - 6 } & $\begin{array}{c}\text { Furnace } \\
\text { temperature } \\
\left({ }^{\mathbf{0}} \mathbf{C}\right)\end{array}$ & $\begin{array}{c}\text { Heating die } \\
\text { temperature } \\
\left({ }^{\mathbf{0}} \mathbf{C}\right)\end{array}$ & $\begin{array}{c}\text { Linear } \\
\text { pulling } \\
\text { Speed } \\
(\mathbf{m} / \mathbf{m i n})\end{array}$ & $\begin{array}{c}\text { Flexural } \\
\text { strength } \\
(\mathbf{M P a})\end{array}$ & $\begin{array}{c}\text { Flexural } \\
\text { modulus } \\
(\mathbf{G P a})\end{array}$ \\
\hline 1 & 160 & 260 & 0.2 & $229.0 \pm 7.3$ & $87.6 \pm 1,3$ \\
\hline 2 & 160 & 240 & 0.2 & $191.7 \pm 7.8$ & $70.4 \pm 2.8$ \\
\hline 3 & 160 & 240 & 0.3 & $237.4 \pm 11.8$ & $80.5 \pm 2.6$ \\
\hline
\end{tabular}


Table 9. Flexural test results on composite bars with and without additive from CF/PP towpregs

\begin{tabular}{|c|c|c|c|c|c|}
\hline \multirow{2}{*}{\multicolumn{2}{|c|}{ Processing parameters }} & \multicolumn{2}{|c|}{$\begin{array}{c}\text { Flexural modulus } \\
(\mathbf{G P a})\end{array}$} & \multicolumn{2}{|c|}{$\begin{array}{c}\text { Flexural strenght } \\
(\mathrm{MPa})\end{array}$} \\
\hline & & \multirow[t]{2}{*}{$\begin{array}{l}\text { Without } \\
\text { additive }\end{array}$} & \multirow[t]{2}{*}{ With additive } & \multirow[t]{2}{*}{$\begin{array}{l}\text { Without } \\
\text { additive }\end{array}$} & \multirow[t]{2}{*}{ With additive } \\
\hline Furnace temperature $\left({ }^{\circ} \mathrm{C}\right)$ & 160 & & & & \\
\hline Heating die temperature $\left({ }^{\circ} \mathrm{C}\right)$ & 260 & \multirow[t]{2}{*}{$90.1 \pm 0.4$} & \multirow[t]{2}{*}{$87.6 \pm 1.3$} & \multirow[t]{2}{*}{$241.2 \pm 1.6$} & \multirow[t]{2}{*}{$229.0 \pm 7.3$} \\
\hline Linear pulling speed $(\mathrm{m} / \mathrm{min})$ & 0.2 & & & & \\
\hline
\end{tabular}

Table 10. Influence of pultrusion conditions on the flexural properties of profiles made from GF/PP towpregs

\begin{tabular}{|c|c|c|c|c|c|c|c|}
\hline \multicolumn{2}{|c|}{ Pultrusion conditions } & \multicolumn{2}{|c|}{ Flexural properties } & \multicolumn{2}{|c|}{ Fibre content } & \multicolumn{2}{|c|}{$\begin{array}{c}\text { Flexural properties / fibre } \\
\text { volume fraction }\end{array}$} \\
\hline $\begin{array}{c}\text { Pre-heating } \\
\text { temperature } \\
\left({ }^{\circ} \mathrm{C}\right) \\
\end{array}$ & $\begin{array}{c}\text { Pultrusion } \\
\text { speed } \\
(\mathrm{m} / \mathrm{min}) \\
\end{array}$ & $\begin{array}{l}\text { Modulus } \\
\text { (GPa) }\end{array}$ & $\begin{array}{c}\text { Strength } \\
(\mathrm{MPa})\end{array}$ & $\begin{array}{c}\text { Mass } \\
(\%)\end{array}$ & $\begin{array}{c}\text { Volume } \\
(\%)\end{array}$ & $\begin{array}{c}\text { Relative } \\
\text { modulus } \\
(\mathrm{GPa})\end{array}$ & $\begin{array}{c}\text { Relative } \\
\text { strength } \\
(\mathrm{MPa})\end{array}$ \\
\hline 170 & 0.2 & $29.1 \pm 0.6$ & $149.2 \pm 14.4$ & 76.1 & 52.2 & $55.7 \pm 1.2$ & $285.2 \pm 27.6$ \\
\hline 170 & 0.3 & $28.6 \pm 1.2$ & $142.3 \pm 16.2$ & 75.4 & 51.3 & $55.8 \pm 2.3$ & $255.0 \pm 31.6$ \\
\hline 180 & 0.2 & $29.5 \pm 0.1$ & $156.1 \pm 5.1$ & 76.5 & 52.8 & $55.9 \pm 0.2$ & $295.6 \pm 9.7$ \\
\hline 180 & 0.3 & $28.6 \pm 0.9$ & $157.7 \pm 12.3$ & 76.0 & 52.1 & $54.9 \pm 1.7$ & $302.7 \pm 23.6$ \\
\hline
\end{tabular}

Table 11. Pultrusion processing parameters for PCT's and Twintex ${ }^{\circledR}$

\begin{tabular}{c|c|c|c|c}
\hline Raw-material & $\begin{array}{c}\text { Heated die } \\
\text { temperature } \\
\left({ }^{\circ} \mathrm{C}\right)\end{array}$ & $\begin{array}{c}\text { Cooled die } \\
\text { temperature } \\
\left({ }^{\circ} \mathrm{C}\right)\end{array}$ & $\begin{array}{c}\text { Pre-heating } \\
\text { temperature } \\
\left({ }^{\circ} \mathrm{C}\right)\end{array}$ & Pulling speed \\
$(\mathrm{m} / \mathrm{min})$
\end{tabular}


Table 12. Microscope images of GF/PP pultruded profiles.

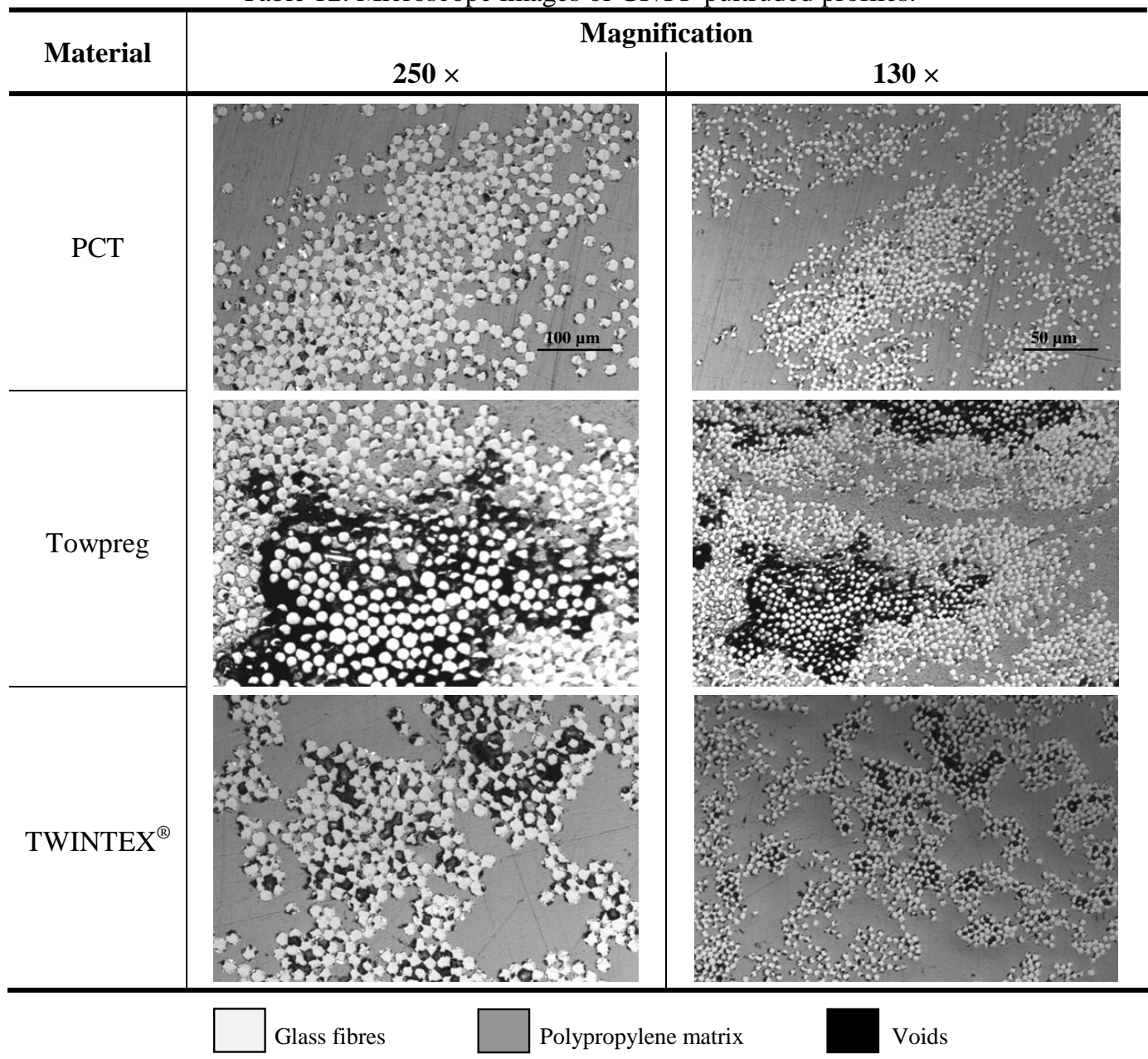

Table 13. CF/PP composite mechanical test results

\begin{tabular}{|c|c|c|c|c|c|}
\hline \multirow{2}{*}{ Test Type } & \multirow{2}{*}{\multicolumn{2}{|c|}{ Property }} & \multicolumn{3}{|c|}{ Pultrusion } \\
\hline & & & \multirow{2}{*}{$\begin{array}{c}\text { Towpreg } \\
90.1 \pm 0.4\end{array}$} & \multirow{2}{*}{$\begin{array}{c}\text { Towpreg with } \\
\text { additive }\end{array}$} & \multirow{2}{*}{$\begin{array}{c}\text { PCT } \\
37.7 \pm 2.2\end{array}$} \\
\hline \multirow{5}{*}{ Flexural } & \multirow{3}{*}{\multicolumn{2}{|c|}{\begin{tabular}{cc}
$\begin{array}{c}\text { Flexure } \\
\text { Modulus } \\
(\mathrm{GPa})\end{array}$ & Experimental \\
\cline { 2 - 2 } & Theoretical \\
Flexure Modulus / Fibre volume \\
fraction $(\mathrm{GPa})$
\end{tabular}}} & & & \\
\hline & & & 98.9 & 98.7 & 62.7 \\
\hline & & & $178.1 \pm 0.8$ & $173.5 \pm 2.6$ & $118.2 \pm 6.9$ \\
\hline & $\begin{array}{c}\text { Flexure } \\
\text { Strength } \\
(\mathrm{MPa})\end{array}$ & Experimental & $241.2 \pm 1.6$ & $229.0 \pm 7.3$ & $158.7 \pm 4.2$ \\
\hline & \multicolumn{2}{|c|}{$\begin{array}{l}\text { Flexure Strength / Fibre volume } \\
\text { fraction }(\mathrm{MPa})\end{array}$} & $476.7 \pm 3.2$ & $453.5 \pm 14.5$ & $497.5 \pm 13.2$ \\
\hline \multirow{5}{*}{ Tensile } & \multirow{3}{*}{\multicolumn{2}{|c|}{\begin{tabular}{cc} 
Tensile & Experimental \\
Modulus & Theoretical \\
\cline { 2 - 2 } & Tensile Modulus / Fibre volume \\
fraction $(\mathrm{GPa})$
\end{tabular}}} & $110.6 \pm 5.9$ & $106.1 \pm 6.3$ & $63.5 \pm 4.3$ \\
\hline & & & 98.9 & 98.7 & 62.7 \\
\hline & & & $218.6 \pm 11.7$ & $210.1 \pm 12.5$ & $199.1 \pm 13.5$ \\
\hline & $\begin{array}{c}\text { Tensile } \\
\text { Strength } \\
(\mathrm{MPa})\end{array}$ & Experimental & $1060.8 \pm 43.1$ & $1129.3 \pm 34.6$ & $636.9 \pm 38.4$ \\
\hline & $\begin{array}{r}\text { Tensile Stre } \\
\text { frac }\end{array}$ & $\begin{array}{l}\text { /Fibre volume } \\
(\mathrm{MPa})\end{array}$ & $2096.4 \pm 85.2$ & $2236.2 \pm 68.5$ & $1996.6 \pm 120.4$ \\
\hline $\begin{array}{l}\text { Inter- } \\
\text { laminar } \\
\text { Shear }\end{array}$ & Interlamin & $\begin{array}{l}\text { hear Strength } \\
\mathrm{Pa})\end{array}$ & $12.3 \pm 0.3$ & $13.0 \pm 0.4$ & $14.0 \pm 0.2$ \\
\hline & re volume fro & on $(\%)$ & 50.6 & 50.5 & 31.9 \\
\hline
\end{tabular}


Table 14. Test results on the processed GF/PP composites

\begin{tabular}{|c|c|c|c|c|c|}
\hline \multirow{2}{*}{$\begin{array}{l}\text { Test } \\
\text { Type }\end{array}$} & \multirow{2}{*}{\multicolumn{2}{|c|}{ Property }} & \multicolumn{3}{|c|}{ Pultrusion } \\
\hline & & & $\begin{array}{l}\text { Commingled } \\
\text { fibres }\end{array}$ & Towpregs & PCT \\
\hline \multirow{5}{*}{ Flexural } & \multirow{2}{*}{$\begin{array}{l}\text { Flexure Modulus } \\
\qquad(\mathrm{GPa})\end{array}$} & Experimental & $26.2 \pm 2.0$ & $28.6 \pm 0.9$ & $16.8 \pm 1.5$ \\
\hline & & Theoretical & 23.8 & 33.1 & 19.1 \\
\hline & \multicolumn{2}{|c|}{$\begin{array}{l}\text { Flexure Modulus / Fibre volume } \\
\text { fraction (GPa) }\end{array}$} & $70.6 \pm 5.4$ & $54.9 \pm 1.7$ & $56.0 \pm 5.0$ \\
\hline & $\begin{array}{l}\text { Flexure Strength } \\
\qquad(\mathrm{MPa})\end{array}$ & Experimental & $595.0 \pm 24$ & $158.0 \pm 12.3$ & $329.0 \pm 30$ \\
\hline & $\begin{array}{r}\text { Flexure Strength } \\
\text { fraction } \\
\end{array}$ & $\begin{array}{l}\text { Fibre volume } \\
\text { MPa) }\end{array}$ & $1603.8 \pm 64.7$ & $303.3 \pm 23.6$ & $1096.7 \pm 100$ \\
\hline \multirow{5}{*}{ Tensile } & \multirow{2}{*}{$\begin{array}{l}\text { Tensile Modulus } \\
\text { (GPa) }\end{array}$} & Experimental & $24.9 \pm 1.1$ & $33.9 \pm 1.5$ & $21.4 \pm 1.5$ \\
\hline & & Theoretical & 23.8 & 33.1 & 19.1 \\
\hline & \multicolumn{2}{|c|}{$\begin{array}{l}\text { Tensile Modulus / Fibre volume } \\
\text { fraction (GPa) }\end{array}$} & $67.1 \pm 3.0$ & $63.5 \pm 2.9$ & $71.3 \pm 5.0$ \\
\hline & $\begin{array}{l}\text { Tensile Strength } \\
(\mathrm{MPa})\end{array}$ & Experimental & $545.9 \pm 31.7$ & $>336.3 \pm 22.3$ & $355.8 \pm 53.2$ \\
\hline & \multicolumn{2}{|c|}{$\begin{array}{c}\text { Tensile Strength / Fibre volume } \\
\text { fraction }(\mathrm{MPa})\end{array}$} & $1471.4 \pm 85.4$ & $>645.5 \pm 42.8$ & $1186.0 \pm 177.3$ \\
\hline $\begin{array}{l}\text { Inter- } \\
\text { laminar } \\
\text { Shear }\end{array}$ & \multicolumn{2}{|c|}{ Interlaminar Shear Strength (MPa) } & $26.8 \pm 1.7$ & $7.5 \pm 0.1$ & $27.8 \pm 0.6$ \\
\hline \multicolumn{3}{|c|}{ Fibre volume fraction (\%) } & 37.1 & 52.1 & 30.0 \\
\hline
\end{tabular}

Table 15. Compared the flexural properties of composite materials under study with those of common use and technical materials

\begin{tabular}{|c|c|c|c|c|c|c|}
\hline \multirow{2}{*}{ Material } & \multirow{2}{*}{$\begin{array}{l}\text { Density } \\
\left(\mathrm{kg} / \mathrm{m}^{3}\right)\end{array}$} & \multicolumn{5}{|c|}{ Flexural properties } \\
\hline & & $\begin{array}{l}\text { Strength } \\
\text { (MPa) }\end{array}$ & $\begin{array}{l}\text { Specific strength } \\
(\mathrm{kN} * \mathrm{~m} / \mathrm{Kg})\end{array}$ & $\begin{array}{l}\text { Modulus } \\
\text { (GPa) }\end{array}$ & $\begin{array}{l}\text { Specific modulus } \\
\left(\mathrm{MN}^{*} \mathrm{~m} / \mathrm{Kg}\right)\end{array}$ & $\begin{array}{c}\text { Modulus }^{1 / 2} / \text { Density } \\
(\mathrm{GPa})^{1 / 2} /\left(\mathrm{Mg} / \mathrm{m}^{3}\right)\end{array}$ \\
\hline CF/PP (from towpreg) [66\%] $]^{\mathrm{a})}$ & 1322.5 & 241.2 & 182.4 & 90.1 & 68.1 & 7.2 \\
\hline GF/PP (from towpreg)[76\%] $]^{\mathrm{a})}$ & 1767.3 & 158.0 & 89.4 & 28.6 & 16.1 & 3.0 \\
\hline GF/PP (from Twintex $\left.{ }^{\circledR}\right)[63 \%]^{a)}$ & 1519.0 & 595.0 & 391.7 & 26.2 & 17.2 & 3.4 \\
\hline $\begin{array}{l}\text { CF/Epoxy laminate (from } \\
\text { prepeg hand layup - AS4 } \\
\text { continuos tows) }[74 \%]^{\text {a) }}\end{array}$ & 1560.0 & 1724.0 & 1105.1 & 134.0 & 85.9 & 7.4 \\
\hline Kevlar/Epoxy UD & 1360.0 & 655.0 & 481.6 & 67.0 & 49.2 & 6.0 \\
\hline $\begin{array}{l}\text { GF/PP compression molded } \\
\text { (from UD melt-impregnated } \\
\text { prepegs) }[60 \%]^{\text {a) }}\end{array}$ & 1480.0 & 570.0 & 385.1 & 22.0 & 14.9 & 3.2 \\
\hline GF Pultrusion [60-80\% $]^{\mathrm{a})}$ & $\begin{array}{r}2016.0- \\
2288.0\end{array}$ & $345.0-552.0$ & $171.1-241.3$ & $31.0-41.0^{\mathrm{e})}$ & $15.3-17.9$ & $2.8-3.2$ \\
\hline Stainless steel $(304)^{b)}$ & 8000.0 & $517.0^{d)}$ & 64.6 & $193.0^{\mathrm{e})}$ & 24.1 & 1.7 \\
\hline Carbon Steel $(1020)^{\mathrm{b})}$ & 7870.0 & $400.0^{d)}$ & 50.8 & $206.0^{\mathrm{e})}$ & 26.2 & 1.8 \\
\hline Aluminium alloy $(5052-\mathrm{H} 34)^{\mathrm{c})}$ & 2680.0 & $262.0^{\mathrm{d})}$ & 97.8 & $70.0^{\mathrm{e})}$ & 26.1 & 3.1 \\
\hline Aluminium alloy $(3003-\mathrm{H} 14)^{c)}$ & 2730.0 & $152.0^{\mathrm{d})}$ & 55.6 & $69.0^{\mathrm{e})}$ & 25.2 & 3.0 \\
\hline Aluminium $(1100)^{b)}$ & 2710.0 & $90.0^{\mathrm{d})}$ & 33.2 & $69.0^{\mathrm{e})}$ & 25.5 & 3.1 \\
\hline Epoxy & 1150.0 & $110.0-115.0$ & $95.7-100$ & $3.0-3.2$ & $2.6-2.8$ & $1.5-1.6$ \\
\hline Polyester & 1200.0 & $80.0-123.0$ & $66.7-102.5$ & $3.0-3.5$ & 2.9 & 1.5 \\
\hline PEEK & 1292.0 & 110.2 & 85.2 & $3.9-2.8$ & $2.2-3.0$ & 1.4 \\
\hline PPS & 1350.0 & $96.0-151.0$ & 71.1-111.9 & 3.4-4.1 & $2.5-3.0$ & $1.4-1.5$ \\
\hline PA-6 & 1115.0 & $69.0-117.3$ & $61.8-105.2$ & $1.9-2.8$ & $1.7-2.5$ & $1.2-1.5$ \\
\hline PC & 1215.0 & $81.4-93.2$ & $66.9-76.7$ & 2.1-2.4 & $1.8-2.0$ & $1.2-1.3$ \\
\hline PP & 909.5 & $44.8-55.2$ & $49.3-60.7$ & $0.8-1.7$ & $0.9-1.7$ & $1.0-1.4$ \\
\hline
\end{tabular}




\section{Figures}

1
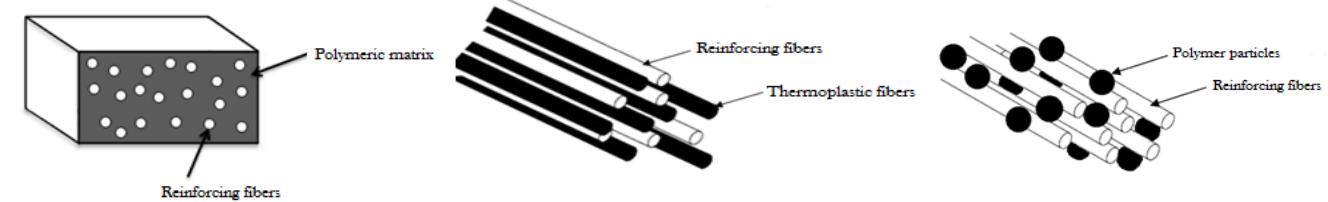

a) Pre-consolidate tapes (PCTs) b) Commingled fibres

Figure 1. Pre-impregnated products under study
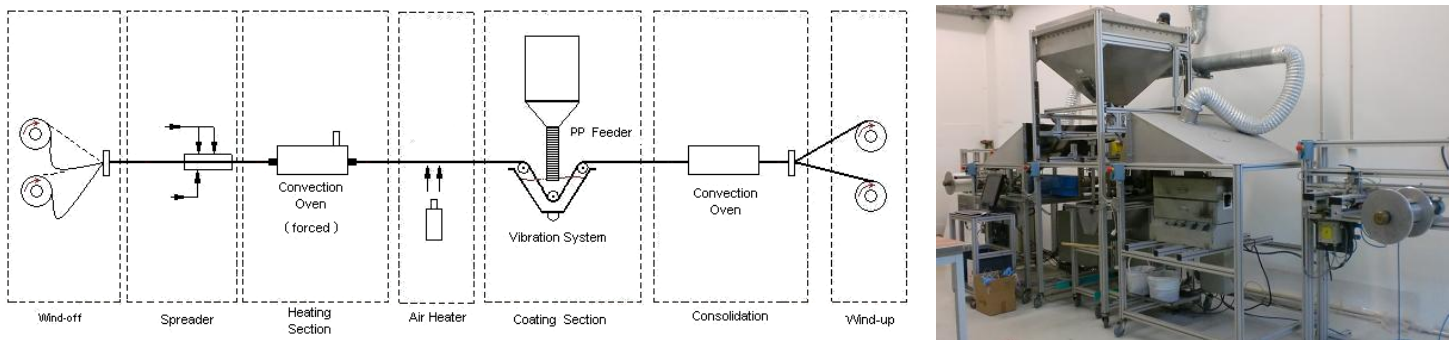

Figure 2. Powder coating line setup.

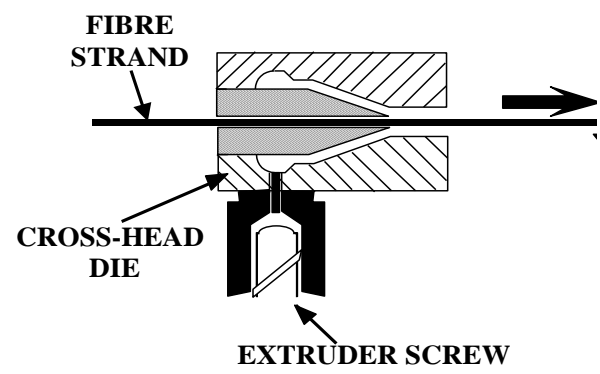

Figure 3. Cross-head extrusion die

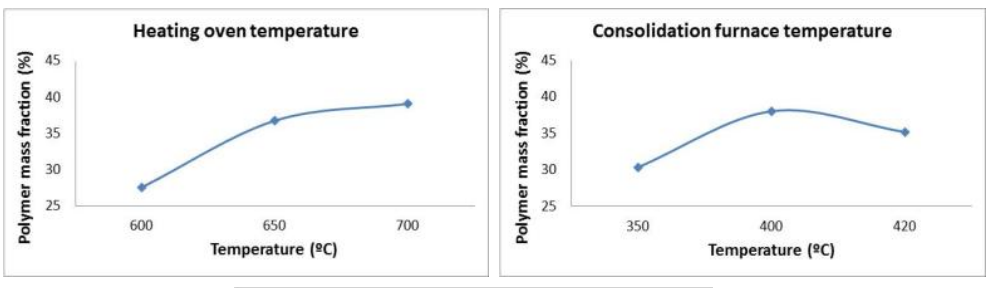

Linear pull speed

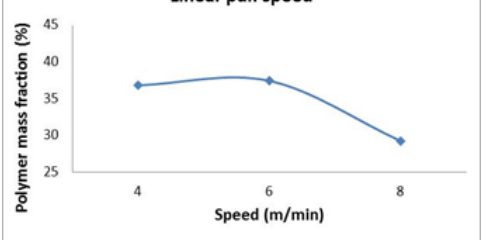

Figure 4. Variation of towpreg polymer content with processing parameters
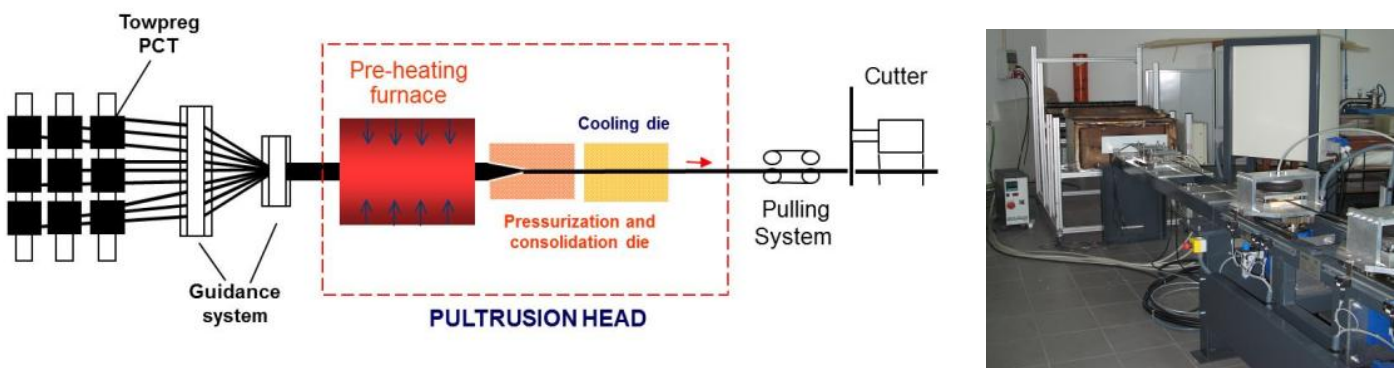

Figure 5. Schematic diagram and overview of the pultrusion line 


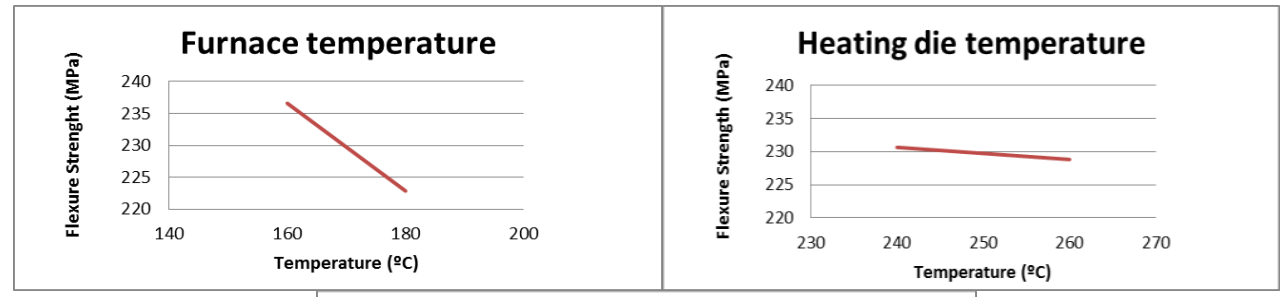

Figure 7. Variation of the flexural modulus with the selected processing parameters

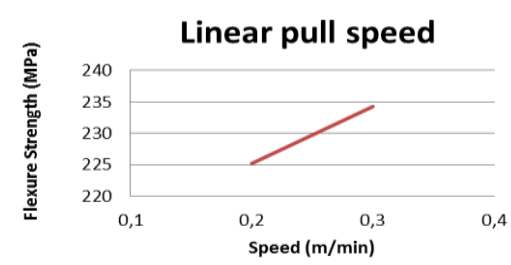

Figure 8. Variation of the flexural strength with the selected processing parameters

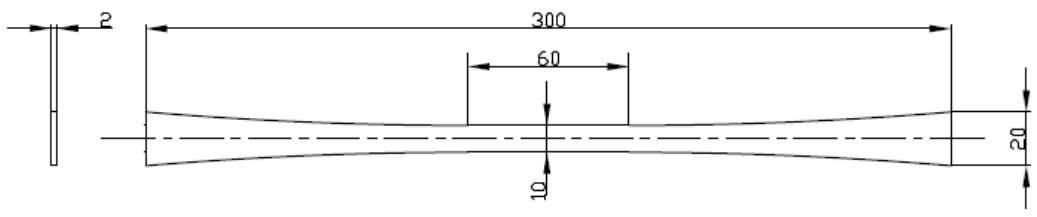

Figure 9. Geometry of the tensile test specimens
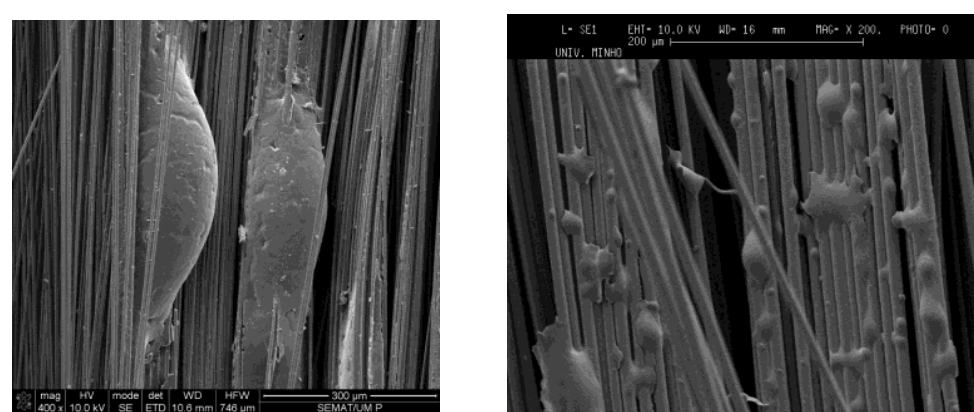

a) CF/PP towpreg (magnification 400x)

b) GF/PP towpreg (magnification 200x)

Figure 10. Typical CF/PP and GF/PP towpreg SEM micrographs 
Towpreg with additive

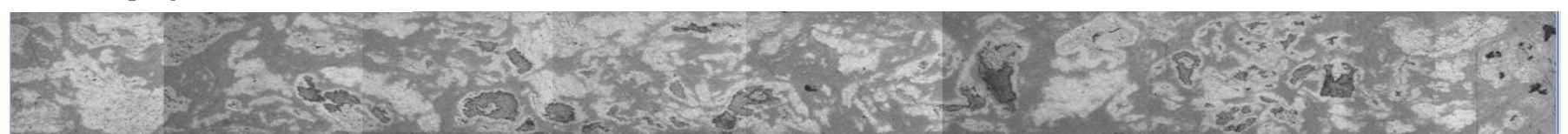

\section{PCT}

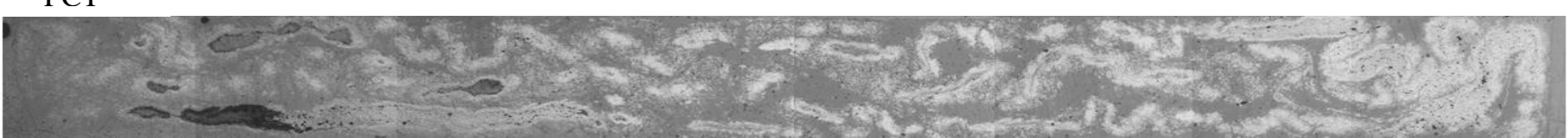

Carbon fibres impregnated with polypropylene;

Polypropylene matrix;

Dry carbon fibres;

Voids.

Figure 11. Optical micrographs of the CF/PP pultruded profiles cross-sections $\left(20 \times 2 \mathrm{~mm}^{2}\right)$

(magnification of $6.25 \times$ )

Total pultruded composite cross-section (5x)

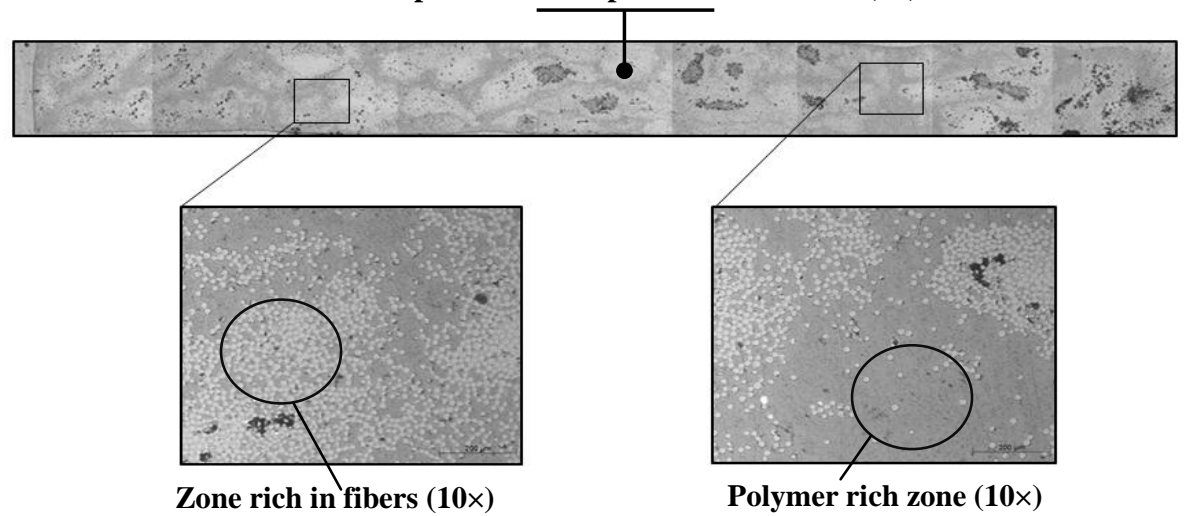

Figure 12. Cross-section $\left(20 \times 2 \mathrm{~mm}^{2}\right)$ of pultruded profiles from GF/PP towpregs observed under optical microscopy

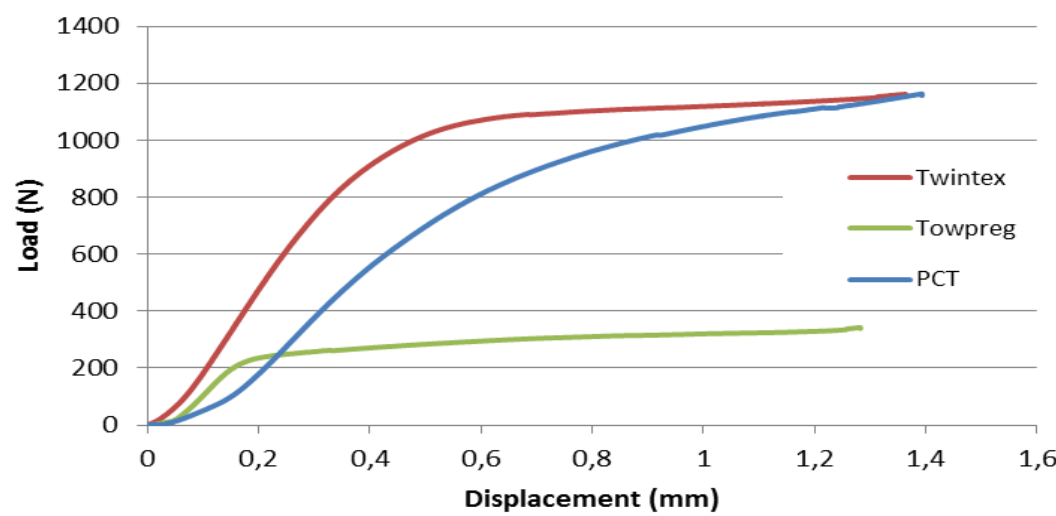

Figure 13. Short beam test results of pultruded composites from GF/PP pre-impregnated materials 